\title{
Biodiversity of the Coccidia (Apicomplexa: Conoidasida) in vertebrates: what we know, what we do not know, and what needs to be done*
}

\author{
Donald W. Duszynski
}

Department of Biology, University of New Mexico, New Mexico, USA

\begin{abstract}
Over the last two decades my colleagues and I have assembled the literature on a good percentage of most of the coccidians (Conoidasida) known, to date, to parasitise: Amphibia, four major lineages of Reptilia (Amphisbaenia, Chelonia, Crocodylia, Serpentes), and seven major orders in the Mammalia (Carnivora, Chiroptera, Lagomorpha, Insectivora, Marsupialia, Primates, Scandentia). These vertebrates, combined, comprise about 15,225 species; only about 899 (5.8\%) of them have been surveyed for coccidia and 1,946 apicomplexan valid species names or other forms are recorded in the literature. Based on these compilations and other factors, I extrapolated that there yet may be an additional 31,381 new apicomplexans still to be discovered in just these 12 vertebrate groups. Extending the concept to all of the other extant vertebrates on Earth; i.e. lizards (6,300 spp.), rodents plus 12 minor orders of mammals (3,180 spp.), birds (10,000 spp.), and fishes (33,000 spp.) and, conservatively assuming only two unique apicomplexan species per each vertebrate host species, I extrapolate and extend my prediction that we may eventually find 135,000 new apicomplexans that still need discovery and to be described in and from those vertebrates that have not yet been examined for them! Even doubling that number is a significant underestimation in my opinion.
\end{abstract}

Keywords: Amphibia, Amphisbaenia, Carnivora, Chelonia, Chiroptera, Crocodylia, Insectivora, Lagomorpha, Marsupialia, Primates, parasitic protists, Scandentia, Serpentes, systematics, taxonomy

*This article is adapted from the opening plenary lecture, 8th International Symposium of Parasitology, Shijiazhuang, Hebei Provence, China, 16-20 October 2019.

The phylum Apicomplexa Levine et al. 1980 (emended by Adl et al. 2012), comprises a large group of obligate, intracellular protist parasites. Initially, these organisms were called 'Sporozoa,' a catch-all name for Protozoa that were not amoeba, flagellates, or ciliates. The most complete early compilation of the Sporozoa was by Labbé (1899), who listed about 180 species in 70 genera of gregarines and 60 species in 22 genera of Coccidia (see Levine 1988). As our knowledge increased, understanding the lineage(s) of certain sporozoans became unwieldy because there were few true evolutionary relationships between/among the organisms included therein, some of which were not even spore formers.

In 1964, a committee of the Society of Protozoologists revised the phylum Protozoa dividing the former Sporozoa into two subphyla, Sporozoa and Cnidospora (Honigberg et al. 1964), but this classification scheme had a number of deficiencies. About the same time, a technical revolution began in the early 1950s, continued through the 1960s and into most of the 1970s, with the widespread use of the
Transmission Electron Microscope (TEM) to study biological specimens. A plethora of publications examined and documented the fine structure of 'zoites' belonging to many different protists, including sporozoans. Eventually, a pattern emerged that showed several common, consistently shared structures at the more pointed end of certain life stages; when present, these structures, in whatever combination, were termed the 'apical complex.'

The turning point for the classification of the Sporozoa was 1970, when Frenkel et al. (1970), Hutchison et al. (1970), and Sheffield and Melton (1970) discovered the asexual and sexual stages of Toxoplasma gondii (Nicolle et Manceaux, 1908) in the small intestine of cats, and that the fertilised macrogametes produced oocysts to be discharged in cat faeces that were similar to those of Isospora bigemina (Stiles, 1891) from dogs. At the time, protozoologists were trying to define a more phylogenetically relevant suite of characters to delineate their organisms, and it was Norman D. Levine, from the University of Illinois, who suggested a solution. He came up with the name 'Apicom- 
plexa' for a new subphylum that used the presence of the apical complex (polar ring, rhoptries, micronemes, subpellicular tubules, micropores, and often a conoid) in some life history stage as the major unifying feature. He also removed the myxosporeans and microsporidians from the Sporozoa, listing them as separate subphyla. Unfortunately, Levine's new name was presented in an abstract booklet following the Second International Congress of Parasitology in Washington, D.C. USA, in September, 1970 (Levine 1970). It was not published in a peer-reviewed journal and, thus, was not universally accepted for a decade until another Committee on Systematics and Evolution (of the Society of Protozoologists) codified Apicomplexa as the distinct phylum name (Levine et al. 1980) for the old Sporozoa. Adl et al. (2005) tried to accurately reflect relatedness of various lineages, based on available evidence, and produced a classification scheme with the utilitarian purpose of categorising diversity in a practical manner and this scheme was later modified/updated twice (Adl et al. 2012, 2019) so that it could be understood and used by the non-specialist.

Nine decades after Labbé's (1899) compilation of the Sporozoa, Levine (1988) made the next and, to date, last comprehensive list of apicomplexan parasites. Using standard host species assemblages from vertebrate biologists of the time (e.g., Nowak and Paradiso 1983 for mammals), he (Levine 1988, table 1, p. 7) estimated there were about 41,700 vertebrate species on Earth that had 3,338 named species of apicomplexans known to him, of which 1,116 named species were included in the Coccidia. Based on Levine's extrapolation $(1988$, p. 6), he wrote, “....even if we limit ourselves to vertebrates, there still would be perhaps 60,000 apicomplexan species yet to be named." Unfortunately, there has been no similar compilation in the last $30+$ years of how many apicomplexans are now known from any vertebrate lineages and with no baseline data, how does one predict how many apicomplexan species are yet to be named?

Adl et al.'s classification schemes (2005, 2012, 2019) divided the Apicomplexa into two major lineages, the Aconoidasida Mehlhorn et al., 1980, which includes the Haemospororida Danilewsky, 1885 and the Piroplasmorida Wenyon, 1926, and the Conoidasida Levine, 1988, now with three major lineages (as per Adl et al. 2019), the Gregarinasina Dufour, 1828, Blastogregarina Chatton et Villeneuve, 1936, and Coccidia Leuckart, 1879. In this review I am concerned only with the Coccidia.

Coccidia were among the first protozoans ever visualised when Antonie van Leeuwenhoek, in 1674, saw structures in the bile of a domestic rabbit that likely were oocysts of Eimeria stiedai (Lindemann, 1865) (reviewed in Duszynski and Couch 2013, pp. 2-3). Unfortunately, there are shortfalls to the way we use surveys to discover and document coccidian species (see Discussion), a process that has steadily progressed, albeit slowly, for almost 350 years. Compiling the information from the literature is difficult because it is spread out across many (sometimes obscure, out-of-print, regional) journals in many different languages, and crosses many different biological disci- plines (e.g., taxonomy, systematics, human, zoo and veterinary medicine, wildlife diseases, etc.) across all vertebrate lineages. Further, since protists, including those with resistant cysts or oocysts, do not preserve well (Marchiondo and Duszynski 1978, 1988, Duszynski and Gardner 1991), there are no fossils collecting dust in museums around the world to examine.

Since about 1995, my colleagues and I have been working to document the total numbers of some coccidians in various host lineages. Based on our work - still unfinished - I believe Levine's (1988) prediction of "perhaps 60,000 apicomplexan species" is a gross underestimate of the number and biodiversity of just the Coccidia that remain to be discovered in vertebrate species. This review presents a brief synopsis of our work on the coccidian parasites of 12 vertebrate lineages. However, time is of the essence because the threats to biodiversity grow more dire every year. A 2019 report from the United Nations estimated that about a million species are now at risk of extinction, and that biodiversity is declining hundreds of times faster than the normal rate - a pace never before seen in human history (Smith 2020, p. 48, Stein 2020, p. 24). This loss of biodiversity did not include, or think about including, the loss of all the parasite species from these million species now at risk! This review is a plea for help to complete the survey of extant vertebrate lineages before they and their parasites are gone forever. And it would be especially helpful if more parasitologists will begin to undertake tasks of revisionary summaries for those groups in which we do know something of their parasite communities.

\section{MATERIALS AND METHODS}

A number of research colleagues (see Acknowledgements) and I have attempted to summarise the literature on the coccidian parasites known from 12 vertebrate host lineages including amphibians (1), reptiles (4) and mammals (7). Some of our early research efforts focused only on intestinal coccidians (Eimeriidae), while some of the later reviews were more inclusive with lists of intestinal, tissue, and/or blood apicomplexans; thus, the data summarised here is uneven and category-biased. To date, these 12 compilations resulted in six monographic works including Amphibia (Duszynski et al. 2007), Amphisbaenia (McAllister and Duszynski 2019), Chiroptera (Duszynski 2002), crocodiles (Duszynski et al. 2020), insectivores (Duszynski and Upton 2000), and primates and Scandentia (Duszynski et al. 1999), and five books on Serpentes (Duszynski and Upton 2010), Lagomorpha (Duszynski and Couch 2013), Chelonia (Duszynski and Morrow 2014), Marsupials (Duszynski 2016), and carnivores (Duszynski et al. 2018). This overview gives a reasonably good estimate of the updated biodiversity of apicomplexans now known to parasitise these vertebrate groups. From these known data, I used simple extrapolation (no. apicomplexans known/no. host species examined $=\mathrm{x}$, the no. apicomplexans to be discovered/no. host species still to be examined for apicomplexans) to 'guesstimate' the number of apicomplexans yet to be discovered in the remaining vertebrates that still need to be surveyed for these parasites. These estimates assume that existing trends will continue and current or similar methods of collecting such data will remain the same. I understand that such unquantified numbers, beyond the range of values 
known, is subject to great uncertainty and pose a higher risk of producing meaningless results, but it gives us a starting point and something to think about.

In this and previous reviews we omitted all the Aconoidasida, including the Haemospororida (Plasmodium Marchiafava et Celli, 1885, Haemoproteus Kruse, 1890, Leucocytozoon Sambon, 1908, etc.) and the Piroplasmorida (Babesia Starcovici, 1893, Theileria Bettencourt, França et Borges, 1907, etc.) and focused mainly on the Conoidasida that includes the Coccidia. None of the Gregarinasina, also within the Conoidasida, are included here because, to my knowledge, they only parasitise invertebrates.

\section{RESULTS}

Below, I catalogue the abundance of apicomplexan biodiversity for 12 vertebrate groups that include the Amphibia, four Reptilia, and seven Mammalia lineages.

\section{Amphibia (frogs, toads, salamanders, caecilians)}

Herpetology taxonomists estimate there are $\sim 8,120$ extant species of amphibians in 75 families and 554 genera (Frost 2020). Duszynski et al. (2007) looked exclusively at the known apicomplexans in the Eimeriidae and found only 15 (20\%) families, 28 (5\%) genera and $45(0.6 \%)$ amphibian species had been examined and documented to be hosts for one or more apicomplexans. A few new forms/ species have been added to that list since 2007, but not many (Jirků et al. 2009, Bartošová-Sojková 2015), so the host species examined, and the parasite species known from them, has not changed to any degree.

From these 45 amphibian species known to have eimeriid apicomplexans described from them, there are about 52 species including: 38 Eimeria Schneider, 1875, 11 Isospora Schneider, 1881, two Goussia Labbé, 1896, one Hyaloklossia Labbé, 1896, and 38 species incertae sedis, nomina nuda, species inquirendae, or 'other' forms mentioned. Combining the 52 eimeriid and 38 'other' apicomplexan morphotypes recorded through 2007, 90 apicomplexans were found in 45 amphibian species. Given that 8,075 amphibian species have never been surveyed for apicomplexans, simple extrapolation estimates that $\sim 16,150$ more eimeriid Apicomplexa species remain to be discovered just in amphibians alone (Table 1).

In working through this survey data, many questions arise including:

- Why have so few amphibian species been examined for apicomplexans?

- Why can some coccidia infect multiple host species but not cross genus or family boundaries, while others seem to be highly host-specific (or is this just sampling error)?

- Why do Goussia species only infect tadpoles, but metamorphosed and adult frogs are never infected with members of this genus?

- Oocysts recovered from salamanders and caecilians have thick walls (exogenous sporulation) vs. the thin walls (endogenous sporulation) of oocysts reported in most frog species. Do they represent different lineages?

- Species of Eimeria and Goussia from frogs and toads generally lack wall-forming bodies in their macrogamonts ( $\sim$ to some piscine coccidia). Are these shared characters 'primitive' and similar to those in both fish and some invertebrates?

\section{Reptilia: Amphisbaenia (legless lizards)}

Legless lizards are mostly small ( $<150 \mathrm{~mm}$ long), legless squamates widely distributed throughout Africa, the Americas and the Caribbean, Europe, and the Middle East. Currently, there are six recognised families with 20 genera and 198 species (Uetz et al. 2020). McAllister and Duszynski (2019) compiled all the taxonomic and survey literature on what was known about their coccidian parasites (Eimeriidae only) and found two (33\%) families, three (15\%) genera and only four (2\%) amphisbaenian species had been examined and documented to have apicomplexans described from them. To my knowledge, no additional eimeriid parasites have been described since their work.

From these four amphisbaenian species known to have eimeriid apicomplexans, we know there are about 11 coccidia spp. including: three Choleoeimeria Paperna et Landsberg, 1989, one Eimeria, four Isospora, and three 'other' forms (species incertae sedis, species inquirendae, etc.) mentioned. Thus, through 2019, 11 coccidian types have been reported in the four amphisbaenian species. Given that 194 amphisbaenians have never been surveyed for apicomplexans, a conservative extrapolation suggests that $\sim 543$ more apicomplexan species remain to be discovered in the legless lizards alone (Table 1).

We do not know very much about amphisbaenian apicomplexans, but:

- Why are coccidia in all legless lizards limited to species with only direct life cycles? Or is this just sampling error due to the lack of more substantial research in this area?

\section{Reptilia: Crocodylia (alligators, caimans, crocodiles)}

The order Crocodylia (suborder Eusuchia) includes alligators, caimans, crocodiles, and ghavials. These iconic predators are cosmopolitan in distribution, inhabiting subtropical and tropical locations and, at present, there are three families composed of ten genera and 27 species (Uetz et al. 2020). Numerous surveys have provided a wide variety of parasite lists from the Crocodylia, but many of them are trivial with small sample sizes of one or two animals within which protist parasites only are identified to genus.

Recently, Duszynski et al. (2020) compiled what they believe is all the taxonomic and survey literature on blood and intestinal apicomplexans known from the Crocodylia and found that each of the three families have had species documented, as have 8/10 (80\%) genera, and 17/27 (63\%) species. From these 17 Crocodylia species with apicomplexan gut or blood parasites, we know there are $\sim 16$ valid coccidia spp. including: eight Eimeria, one Haemogregarina Danilewsky, 1885; four Hepatozoon Miler, 1908, two Isospora, one Progarnia Lainson, 1995, and 46 'other' forms (nomina nuda, species inquirendae, etc.) mentioned. Thus, 62 apicomplexan forms have been seen at some time in 17 crocodile species; extrapolating to what might be, suggests that $\sim 36$ more of these species remain to be 
discovered from the ten extant species of Crocodylia that have not yet been surveyed for them (Table 1).

The survey literature on crocodile apicomplexans brings two questions to mind:

- Why do crocodiles not have species of Sarcocystis Lankester, 1882, or is it just that no one has looked?

- Can the Coccidia provide clues to understand the evolutionary relationship between crocodiles and birds, thought to be more closely related, than are the crocodiles to other reptile groups?

\section{Reptilia: Serpentes (snakes)}

Duszynski and Upton (2010) used Uetz (2007) as the taxonomic authority on living species of snakes; Uetz (2007) listed 17 families, 457 genera and 3,180 species at that time. Today, with the advent of newer field studies and some gene sequencing to sort out a number of cryptic species, Uetz et al. (2020) identified 30 families (23 subfamilies), 563 genera, and 3,805 species of Serpentes. Duszynski and Upton (2010) listed and discussed 156 named species of coccidia in snakes that included 52 species of Caryospora Léger, 1904, two of Cryptosporidium Tyzzer, 1907, four of Cyclospora Schneider, 1881, 66 of Eimeria, seven of Isospora, 22 of Sarcocystis, two of Tyzzeria Allen, 1936, and one species of Wenyonella Hoare, 1933. Since their treatise, at least (or only) three additional species of Sarcocystis (Hu et al. 2012, Roberts et al. 2015, Verma et al. 2017), four species of Caryospora (Daszak et al. 2011a, McAllister et al. 2012a, Viana et al. 2013, de Santana Miglionico and Viana 2017), two species of Eimeria (Alyousif et al. 2003, Daszak et al. 2011b), one species of Choleoeimeria (Abdel-Baki et al. 2014a), two species of Isospora (McAllister et al. 2015, 2016), and one species of Hepatozoon (Tomé et al. 2013) have brought the total of named of species coccidia in snakes to 169 .

Additionally, at least a half dozen species inquirendae and other non-specific identifications - and perhaps a few others I missed - have been made (e.g., Tomé et al. 2013, McAllister et al. 2015). These descriptions and notes add six species, two genera and one family to the list of Serpentes not previously reported to harbour apicomplexans. Thus, there are now $\sim 321$ apicomplexan forms reported from all Serpentes worldwide and these are found in only $7 / 30(23 \%)$ families, 112/563 (20\%) genera, and 214/3,805 (6\%) species. From these known numbers, I extrapolate there are $\sim 5,387$ new apicomplexan species yet to be discovered in snakes (Table 1) when all species can be thoroughly examined over each one's home range.

In looking at the data on snake apicomplexans in 2010, we unfortunately did not give attention to the blood parasite literature from snakes so an obvious question is:

- How many blood apicomplexans will be discovered in snakes when someone finally begins a revisionary summary of all those systematic surveys (e.g., Saoud et al. 1996, Abdel-Baki et al. 2014b)?

\section{Reptilia: Chelonia (turtles, tortoises, terrapines)}

Duszynski and Morrow (2014) summarised and discussed the gastrointestinal Coccidia known from turtles at the time. They listed 71 named Coccidia that included one species of Caryospora; 66 of Eimeria, three of Isospora, and one of Sarcocystis. Additionally, they documented that an additional 28 forms had entered the literature, but without enough information to name them as good species, so they placed them into tentative categories of species inquirendae, incertae sedis, nomina nuda, or 'other' until more information could be provided by future investigations. In 2013, the reptile database listed turtles of the world to have 14 families, 92 genera, and 328 species. New phylogenetic and taxonomic analyses now has expanded turtle taxonomy to 14 families (within 5 superfamilies), 95 genera and 352 species (Uetz et al. 2020).

Since Duszynski and Morrow's treatise (2014), I find that only one new Isospora (Hnida 2015) and one new species of Haemogregarina (Telford et al. 2009) have been added to named species from turtles. However, three very interesting molecular phylogenetic studies on what we currently think are familiar coccidian genera (e.g., Caryospora, Eimeria, Goussia) have shed more light on what we do not know about turtle coccidians, and likely has contributed at least five more species inquirendae to the apicomplexan 'species' mix in turtles.

Chapman et al. (2016) examined what was, presumably, Caryospora cheloniae Leibovitz, Rebell et Boucher, 1978 in 11 dead green sea turtles, Chelonia mydas (Linnaeus), and amplified the $18 \mathrm{~S}$ rDNA region of the coccidian parasite(s) present in their tissues. All 11 turtles were confirmed to have positive infections and their results indicated the presence of two distinct parasite genotypes; one was associated with the brain, gastrointestinal tract, and lung, and the second genotype with the thyroid and kidney. Their first genotype placed closest to the genus Schellackia Reichenow 1919 (Lankesterellidae Labbé, 1899) and their second genotype was paraphyletic to the eimeriids. They concluded that these genotypes represented different species and raised the question about the current taxonomic placement of the genus Caryospora within the Eimeriidae.

Ferguson et al. (2016) found stages resembling coccidia in the adrenal glands of leatherback sea turtles, Dermochelys coriacea (Vandelli), and two partial 18S rDNA genetic sequences from adrenal gland tissue lesions formed a clade within the Eimeriidae. One of these sequences was identical to sequences from unsporulated oocysts found in the faeces of the infected turtle, but without sporulated oocysts they did not make a generic or specific identification of this parasite.

Finally, Hofmannová et al. (2019) found oocysts in the faeces of leopard tortoises, Stigmochelys pardalis (Bell). After sporulation, these oocysts were Eimerial Goussia-like and were transmissible to two additional $S$. pardalis, two Testudo hermanni Gmelin, two T. horsfieldii Gray, and one Centrochelys (syn. Geochelone) sulcata (Miller). Hofmannová et al. (2019) neglected to name their new coccidium because "to affiliate it to any of the existing genera is complicated by generally unclear phylogeny of coccidia from poikilothermic hosts."

Thus, there are now about 106 apicomplexans reported from all Testudines worldwide and these are found in 10/14 
(71\%) families, 34/95 (36\%) genera, but only in 67/352 (19\%) species. Given these known numbers, I extrapolate that there are still $\sim 456$ new apicomplexan species yet to be discovered in turtles when all species are examined over their home ranges (Table 1).

In working through this survey literature, several questions come to mind:

- Endogenous stages of at least four species of Eimeria and one species of Caryospora in turtles show pronounced pathology and cause death in green sea turtles and other young turtles in mariculture. Why are these species so pathogenic in turtles, whereas in other turtle species members of these protist genera seldom become pathogenic in their natural hosts?

- Newly-discovered intranuclear Eimeria-like species show their endogenous development in multiple tissues (liver, lungs, kidneys, intestines), and can be highly pathogenic. Why?

- Some species of Eimeria in turtles show little host specificity (e.g., Eimeria mitraria [Laveran et Mesnil, 1902]) Doflein, 1909 has been reported in 15 turtle species in 12 genera of three families), while 50 other turtle Eimeria are only known from a single host species. Is this real or sampling error?

- There is a deep evolutionary divide between the Cryptodira/Pleurodira; species of Eimeria in the former discharge oocysts that sporulate exogenously vs. endogenous sporulation of oocysts discharged by species from the Pleurodira. A real phenomenon or sampling error?

\section{Mammalia: Afrosoricida, Erinaceomorpha, Macroscelidea, Soricomorpha (Insectivores: hedgehogs, moles, shrews, and their relatives)}

Insectivores are the most primitive of all placental mammals and are thought to be the group from which all present-day mammals evolved. Wilson and Reeder (2005) place the members of the former order Insectivora into four orders, eight families, 74 genera, 503 species, whereas some others (D'Agostino 2014) limit the taxonomic divisions to six families. For consistency, I prefer Wilson and Reeder's (2005) taxonomy and use it for all the mammalian orders in this paper.

Duszynski and Upton (2000) reviewed and evaluated all published species descriptions in the coccidian genera Cyclospora, Eimeria and Isospora known then to infect insectivores. Using Wilson and Reeder's (1993) classification, they recorded that 5/7 (71\%) families, 19/66 (29\%) genera, but only $38 / 428(9 \%)$ extant insectivore species had eimeriid coccidia recorded from them that included 48 species of Eimeria, 22 of Isospora, five of Cyclospora, and 45 other forms (species inquirendae, incertae sedis, etc.) not sufficiently defined to assign a binomial to them.

Since Duszynski and Upton's (2000) review, additional species of Coccidia reported in the world's literature include at least two species of Cryptosporidium (Ziegler et al. 2007, Kváč et al. 2014, Song et al. 2015); two of Cyclospora (McAllister et al. 2018); eight of Eimeria (Duszynski et al. 2003, Modrý et al. 2005, Duszynski 2008, Couch et al. 2011, Lynch and McAllister and Seville 2017, McAllister et al. 2018); one of Elleipsisoma Franca, 1912 (Mohamed and Molyneux 1984, Mohamed et al. 1987, a red blood cell parasite of moles, transmitted by mites); one of Hepatozoon (Uilenberg 1970); Neospora caninum Dubey, Carpenter, Speer, Topper et Uggla, 1988 (Meerburg et al. 2012); Toxoplasma gondii (Meerburg et al. 2012), and more than five forms not defined with binomial names (e.g., Graczyk et al. 1998, Milek and Seville 2003, Ziegler et al. 2007).

Using Wilson and Reeder (2005) and the recent discoveries of apicomplexans since 2000, there are now about 141 coccidian forms known from all Insectivora; these are found in 3/4 (75\%) orders, 5/8 (63\%) families, 24/74 (32\%) genera, but only $64 / 503(13 \%)$ species. Given these data, I extrapolate there are still $\sim 966$ new apicomplexan species yet to be discovered in insectivores when all their species are examined over each one's home range (Table 1).

This survey data on coccidians in the two related insectivore lineages, shrews vs. moles, motivate one to examine this central conundrum:

- Mole species always are infected with multiple gut eimeriids, whereas shrew species seldom are found to be infected and, when they are, it is almost always with only one eimeriid species. Why? Given the substantial numbers of individuals in both host groups we have collected over the years, this does not seem to be due to sampling error.

\section{Mammalia: Primates (prosimians, anthropoids)}

Duszynski et al. (1999) reviewed and evaluated the published species descriptions in the coccidian genera $C y$ clospora, Eimeria and Isospora known then to infect primates. Using Wilson and Reeder's (1993) taxonomy, they recorded that $7 / 13(54 \%)$ families, $14 / 60(23 \%)$ genera, but only $18 / 233(8 \%)$ extant primate species had coccidia recorded from them that included seven species of Eimeria, eight of Isospora and one of Cyclospora and at least 12 junior synonyms, species inquirendae, or other forms, not sufficiently defined to assign a reliable binomial to them. Wilson and Reeder (2005) thoroughly revised their Mammal Species of the World, relying on various taxonomic and phylogenetic analyses to that date; their revision combined some families and created others, and they now list two suborders composed of 15 families, 69 genera, and 376 species of primates.

Here I update the literature on the Conoidasida of Primates from pre-1999 to the present to include all the coccidian genera and species now known. In addition to the data from Duszynski et al. (1999), these additional genera and species of the Coccidia are reported in the parasitology literature:

- Ten species of Cryptosporidium (Debenham 2017, Table 2, p. 25), from humans and/or other primates; Debenham (2017, Table 11, p. 74, see below) also summarised the literature (7,980 articles in PubMed) from 2000 to 2017 on species/genotypes of Cryptosporidium recorded from non-human primates. - Four species of Cyclospora (Eberhard et al. 1999). 
- Two species of Eimeria (Banlunara et al. 2013, Hofmannová et al. 2018).

- One species of Isospora (Teichroeb et al. 2009).

- Neospora caninum (humans and in Macaca mulatta, experimentally - Dubey et al. 2017).

- Three species of Sarcocystis (S. kortei Castellani et Chalmers, 1909, S. nesbitti Mandour, 1969, S. markusi (Markus, Kaiser et. Daly, 1981), in non-human primates (Dubey et al. 2015).

- Three species of Sarcocystis (S. neurona Dubey et al., 1991, S. hominis (Railliet et Lucet, 1891); S. suihominis (Tadros et Laarman, 1976), in Homo sapiens Linnaeus and in three species of lemurs, a slow loris and a macaque (Klumpp et al. 1994, Yabsley et al. 2007, Elsheikha 2009, Dubey et al. 2015).

- Hammondia hammondi Frenkel, 1974 (experimentally, via oocysts, from cats to one three-year-old male Saguinus nigricollis (Spix) - Dubey and Wong 1978).

- Cystoisospora belli Wenyon, 1923 (Dubey et al. 2019, Dubey 2020).

- Toxoplasma gondii in $>30$ primate species (NeryGuimarães and Franken 1971, Nery-Guimarães et al. 1971, Dubey et al. 1985, Bacciarini et al. 2001, CedilloPeláez et al. 2011, Catão-Dias et al. 2013, Lindsay and Dubey 2014, Santos et al. 2018).

Additionally, there are many coccidian forms that were not defined with binomial names:

- One species of Sarcocystis (see Nery-Guimarães et al. 1971).

- 15 reports of intestinal Sarcocystis forms in H. sapiens (Dubey et al. 2015) in at least eight countries.

- 58 reports of Sarcocystis in H. sapiens either by biopsy or at necropsy from $\sim 20$ countries (Beaver et al. 1979, Dubey et al. 2015 - Tables 4.2, 4.3, pp. 174-175).

- Oocysts of three species of coccidia (Gaetano et al. 2014, Springer and Kappeler 2016).

- >20 Cryptosporidium genotypes (Gómez et al. 1992, 2000, Muriuki et al. 1997, Mosier and Oberst 2000, Dubey et al. 2002, de Silva et al. 2003, Ekanayake et al. 2006, Salzer et al. 2007, Lim et al. 2008, Charles-Smith et al. 2010, Gonzalez-Moreno et al. 2013, Sak et al. 2013, Karim et al. 2014, Ye et al. 2014, Parsons et al. 2015, Sricharern et al. 2016, Debenham 2017 - table 11, p. 74).

- Three species of Cyclospora (Zhao et al. 2013, Marangi et al. 2015).

The above body of work adds three new families, 26 genera and 59 primate species that have been examined at least once for some form of intestinal or tissue-dwelling coccidium. Thus, to date, 10/15 (67\%) families, 40/69 (58\%) genera, but only $77 / 376(20 \%)$ primate species have been examined for coccidians and we now have nine Eimeria, nine Isospora, five Cyclospora, ten Cryptosporidium, N. caninum, six Sarcocystis, H. hammondi, $C$. belli, and $T$. gondii as named species. In addition, there are 112 species inquirendae or other forms that include the following observations: 74 species of Sarcocystis, three of Coccidia, 20 of Cryptosporidium, and three of Cyclospora since Duszynski et al. (1999). These numbers allow me to extrapolate there still may be $\sim 598$ new coccidian apicomplexans still to be discovered in Primates when all species are surveyed over each species' home range (Table 1).

These survey data on primate apicomplexans beg many questions, at least one of which is:

- Why are prosimians infected with species of Eimeria, while other anthropoids never have species of Eimeria found in them?

\section{Mammalia: Scandentia (tree shrews)}

The Scandentia is a small group of mammals that has been difficult to classify. Wilson and Reeder (1993) recognised them as a separate order, closely related to the Primates, with a single family, five genera and 20 species. In their revised taxonomy of all mammal species, Wilson and Reeder (2005, p. 104) made only one minor adjustment to the Scandentia by listing two families, "to more aptly convey the anatomical disparity among the living tree shrews." Thus, Tupaiidae has four genera composed of 19 species while the Ptilocercidae has a single monotypic genus.

Duszynski et al. (1999) compiled the taxonomic and survey literature on what was known about their eimeriid parasites at the time and found only four species in two genera had been examined and were documented to have coccidians. Earlier, Zaman and Goh (1970) had recognised T. gondii as a parasite of Tupaia glis (Diard), a paper that was not included in the Duszynski et al. (1999) review. From 1999 through 2019, I can find only two additional papers added to this parasitological literature. Xiang et al. (2010) discovered and named a new species of Sarcocystis from Tupaia belangeri (Wagner) and Lv et al. (2011) mentioned finding "coccidian oocysts" in the faeces of $T$. belangeri, both studies done in mainland China.

From these five tree shrew species with apicomplexans described from them, we know there are only seven coccidian species: four of Eimeria, one of Sarcocystis, T. gondii, and one species inquirenda. Given such limited survey data for apicomplexans, I extrapolate that $\sim 21$ more apicomplexans remain to be discovered when all species are examined (Table 1).

The limited data on tree shrew apicomplexans beg at least one question:

- Species of Scandentia, to date, are known only to be infected with species of Eimeria. Is this a real phenomenon or is it sampling error due to lack of sufficient survey data?

\section{Mammalia: Chiroptera (bats)}

Duszynski (2002) reviewed and evaluated only the published species descriptions in the coccidian genera Eimeria and Isospora known to infect bats up to that time and he included mention of the "Coccidium sp." of Gruber et al. (1996), but he did not include any of the related families or genera: Adeleidae (e.g., Klossia Schneider, 1875), Cryptosporidiidae (e.g., Cryptosporidium), Eimeriidae (e.g., Dorisia Levine, 1979), Hepatozoidae (e.g., Hepatozoon Miller, 1908), Klossiellidae (e.g., Klossiella Smith et Johnson, 1902), and Sarcocystidae (e.g., Sarcocystis, Toxoplasma Nicolle et Manceaux, 1909). 
Using Wilson and Reeder's (1993) taxonomic scheme, Duszynski (2002) said that 10/17 (59\%) families, 43/177 (24\%) genera, but only 86/925 (8\%) bat species had coccidia recorded from them including 31 named species of Eimeria and eight species inquirendae (a coccidium, six Eimeria, one species of Isospora), not sufficiently defined to assign a reliable binomial to them. Wilson and Reeder (2005) thoroughly revised their Mammal Species of the World, with many changes likely based on phylogenetic analyses of various gene sequences to that date; this resulted in combining some families and creating others that now list 18 families, 202 genera, and 1,116 species of bats.

My intent is to update the literature on the Conoidasida of bats from pre-1999 to the present and to include all the coccidian genera and species now known from the Chiroptera. In addition to the data cited earlier (Duszynski 2002) on 31 species of Eimeria, these additional genera and species of Coccidia are reported in the world's parasitology literature:

- Besnoitia panamensis Schneider, 1965 (experimental Schneider 1966).

- Cryptosporidium parvum Tyzzer, 1912 (Kváč et al. 2015) and C. hominis (Schiller et al. 2016).

- Cryptosporidium bat genotypes III, IV (Kváč et al. 2015), Cryptosporidium bat genotypes II, V, VI, VII (Murakoshi et al. 2016), Cryptosporidium bat genotypes VIII-XI (Schiller et al. 2016), Cryptosporidium bat genotype XII (Murakoshi et al. 2018).

- Dorisa (syn. Dorisiella) harpia (Sinha et Dasgupta, 1978) (Sinha 1979, Levine 1980a, b).

- Nine new Eimeria (McAllister and Upton 2009, McAllister et al. 2004, 2011, 2012b, 2017, Fayed et al. 2011, Tinnin et al. 2012a).

- Klossia variabilis Levine, Ivens et Kruidenier, 1955 (Levine et al. 1955).

- Klossiella killicki Boulard, 1975 (Boulard 1975).

- Nephroisospora eptesici Wünschmann et al., 2010 (Wünschmann et al. 2010).

- Toxoplasma gondii (de Jesus et al. 2017).

Additionally, there are other coccidian forms not defined with binomial names and, thus, only can be species inquirendae:

- Sarcocystis-like, duodenal and renal coccidiosis (Mühldorfer et al. 2011).

- Four Cryptosporidium spp. (Dubey et al. 1998, Morgan et al. 1999, Wang et al. 2013).

- Renal coccidiosis (Gruber et al. 1996).

- One Eimeria sp. sequences (Murakoshi et al. 2016).

- 18S rRNA gene sequence of a parasite in the Sarcocystidae (Wünschmann et al. 2010).

- One Klossiella sp. (Kusewitt et al. 1977).

- One Hepatozoon sp. (genetic evidence of Pinto et al. 2013).

The above work adds one family, 12 genera and 30 bat species that have been examined at least once for some form of a coccidium since Duszynski (2002). To date, 11/18 (61\%) families, 55/202 (27\%) genera, but only 116/1,116 $(10 \%)$ bat species have been examined for coccidians. So we now have: $B$. panamensis, two Cryptosporidium and
11 Cryptosporidium bat genotypes (II-XII), one Dorisa Levine, 1980, 40 Eimeria, one Klossia, one Klossiella, one Nephroisospora Wünschmann et al., 2010 and T. gondii as named species. In addition, there are 19 species inquirendae, junior synonyms, or other forms that include at least: one coccidium, seven species of Eimeria, one of Hepatozoon, one of Isospora, one of Klossiella, two Sarcocystis-like, one duodenal coccidiosis, one renal coccidiosis, and four species of Cryptosporidium since Duszynski's (2002) report. With these known infection data, I extrapolate there still may be $\sim 700$ new apicomplexan species yet to be discovered when all bat species are examined over each species' home range (Table 1). This may be a gross underestimate as Tinnin et al. (2012a) predicted there may be 2,700 species of only Eimeria in all bats worldwide.

Bat apicomplexan data are a bit of a conundrum and raise many questions:

- How do bats that eat insects on the wing become infected via faecal oocysts, while frugivorous bats that land on vegetation are never infected with eimeriid coccidia?

- Is there a phylogenetic rather than an environmental explanation?

- Why do bats seem to harbour species of Eimeria almost exclusively in their intestinal tracts?

- Why have no species of Sarcocystis yet been documented in carnivorous bats?

- Merogony and gamogony of a species of Nephroisospora is reported in kidneys of four genera of aerial insectivorous bats; are these true bat parasites or opportunistic species of Hyaloklossia (frogs) or Klossiella (marsupials)?

\section{Mammalia: Lagomorpha (rabbits, hares, pikas, rock rabbits)}

Lagomorphs share a long and important history with humans. Wilson and Reeder (2005) recognised two extant families (Leporidae, Ochotonidae) with 12 genera and 91 species. Duszynski and Couch (2013) compiled the taxonomic and survey literature on what was known about their coccidian parasites and reported 115 species of conoid-bearing coccidia: two species of Besnoitia Henry, 1913, four of Cryptosporidium, 80 of Eimeria, two of Isospora, five of Sarcocystis, T. gondii, and 21 other forms without adequate descriptions (e.g., species inquirendae, incertae sedis, nomina nuda, etc.) to bear a binomial.

From 2013 through 2019, only two additional papers added new species descriptions to the literature. Tinnin et al. (2012b) described three new species of Eimeria: one from Ochotona hyperborean (Pallas) and two from O. pallasi (Gray), and Cui et al. (2017) described one new species of Eimeria from "Californian rabbits in Hebei Province" (presumably Oryctolagus cuniculus (Linnaeus) from their line drawing of a rabbit, which was not a Lepus Linnaeus but could have been a cottontail).

Therefore, to date, both families, 5/12 (42\%) genera, but only 23/91 (25\%) lagomorph species ever have been examined for the Coccidia and we now have: two species of Besnoitia, four of Cryptosporidium, 84 of Eimeria, two 
of Isospora, five of Sarcocystis and T. gondii as named species. In addition, there are about 30 other forms that include at least the following: 14 species of Eimeria, one of Isospora, 13 Sarcocystis-like, and two species of Cryptosporidium. Using these numbers, I extrapolate there still may be $\sim 381$ new apicomplexan species yet to be discovered in the Lagomorpha when all species are examined over each species' home range (Table 1).

One obvious question immediately comes to mind:

- Why are most rabbits, in almost all surveys, always infected with five or more intestinal coccidia (always species of Eimeria) at all times?

\section{Mammalia: Marsupialia (opossums, kangaroos)}

Within the true Coccidia are two suborders, Adeleorina and Eimeriorina, that differ in their biological development, but members of both lineages are known to parasitise marsupials. Duszynski (2016) said that about 86 parasites from these groups fit taxonomically into seven genera in four families. In the Adeleorina, there are at least 11 species of Klossiella (Klossiellidae) known from marsupials; in the Eimeriorina, six species of Cryptosporidium (Cryptosporidiidae), 56 of Eimeria and one of Isospora (Eimeriidae), and one of Besnoitia, 10 of Sarcocystis, and T. gondii (Sarcocystidae) had been described, along with 68 other forms (e.g., species inquirendae, incertae sedis, etc.). These 154 coccidian forms were known from 14/21 (67\%) families, 46/92 (50\%) genera, and 85/331 (26\%) species of extant marsupials. Since 2016, only Bezerra-Santos et al. (2020) have discovered one new species of Eimeria from an opossum (Didelphis aurita Wied-Neuwied) in Brazil. Thus, I extrapolate there may be $\sim 43$ new apicomplexan species yet to be discovered in all marsupials when all species can be examined over each species' home range (Table 1).

Many questions arise from these data, one of which is:

- Why are species of Klossiella so common in Australian kangaroo kidneys, but uncommon in other mammal lineages in which they have been reported? Or, have we just not looked for them?

\section{Mammalia: Carnivora (canids, felids and relatives)}

Wilson and Reeder (2005) organised all carnivores into two lineages (suborders), the Feliformia (cats and their relatives) with 121 species comprising 54 genera in six families, and the Caniformia (dogs and their relatives) with 165 species comprising 72 genera in nine families. Combined, there are 286 extant species of carnivores in 126 genera assigned to 15 families worldwide. Duszynski et al. (2018) attempted to summarise all conoidasid apicomplexans reported, to that date, from carnivores. They accounted for 209 named and 483 unnamed species of Coccidia (Duszynski et al. 2018-Appendix A) and placed them taxonomically into 12 genera in four families that included: Adeleidae Mesnil, 1903 (Hepatozoon, six named species), Cryptosporidiidae Léger, 1911 (Cryptosporidium, ten named species), Eimeriidae Minchin, 1903 (Caryospora, Cyclospora, Eimeria, Isospora, 52 named species), and Sarcocystidae Poche, 1913, with its three subfamilies, Cystoisosporinae Frenkel, Mehlhorn et Heydorn, 1987 (Cystoisospora Fren- kel, 1977, 53 named species), Sarcocystinae Poche, 1913 (Sarcocystis, Frenkelia Biocca, 1968, 78 named species) and Toxoplasmatinae Biocca, 1957 (Besnoitia, Hammondia Frenkel, 1974, Neospora Dubey, Carpenter, Speer, Topper et Uggla, 1988, Toxoplasma, ten named species).

To date, 14/15 (93\%) families, 80/126 (63\%) genera, and more than half, 172/286 (60\%) carnivore species, have been examined for coccidians and there are five species of Besnoitia, one of Caryospora, ten of Cryptosporidium, one of Cyclospora, 53 of Cystoisospora, 41 of Eimeria, three of Hammondia, six of Hepatozoon, nine of Isospora, one of Neospora, 78 of Sarcocystis and T. gondii, and 483 other forms mentioned (species inquirendae, incertae sedis, etc.). By simple extrapolation, these extensive data suggest there still may be $\sim 456$ new species of the Apicomplexa yet to be discovered in the Carnivora when all species can be examined over each species' home range (Table 1).

Survey data on Carnivora apicomplexans is voluminous generating numerous unanswered questions including one that has intrigued parasitologists since such surveys began: - Why are (valid) species of Eimeria never found in cats (Felidae) or dogs (Canidae), while other families of Carnivora (Mephitidae, Mustelidae, Procyonidae, others) serve as good hosts for many species of Eimeria?

\section{Can we better estimate undiscovered species of Coccidia? This is complicated}

Simple surveys of any vertebrate (or invertebrate) group of extant organisms are not simple because sampling biases in all surveys unavoidably introduce many logistic, sometimes impeding, and often unknown variables that make estimating both host and parasite ranges particularly challenging. And 'guesstimating' the number of new species of the Apicomplexa still awaiting discovery in any host group is even more challenging. Predilections of the survey leader(s), accurate host identifications, and host sample size(s) are three such biases (see Discussion for others).

Survey leader preference. Parasitologists who conduct a survey may be looking only for particular medical (e.g., T. gondii) or zoonotic (Baylisascaris Sprent, 1968) parasites or they may be opportunists sampling only elk hides for ectoparasites at kill stations during hunting season.

Host identifications. The correct identification of hosts from which new parasite species are described is extremely important, especially in groups like amphibians where phylogenetic analyses have changed the taxonomic landscape of these hosts. Two examples will suffice. Scott and Hillis (1990), in one of numerous cases that could be cited, corrected the identification of a Mexican frog from which a new trematode taxon had been described when they documented that the article's authors had identified the type host as a species of Rana Linnaeus that did not occur in Mexico.

Brooks (1993) gave a more stunning and relevant example when he pointed out that leopard frogs in North America were thought to range from the Arctic Circle to Panama; all of them were believed to be a single species, Rana pipiens Schreber, and numerous surveys over decades iden- 


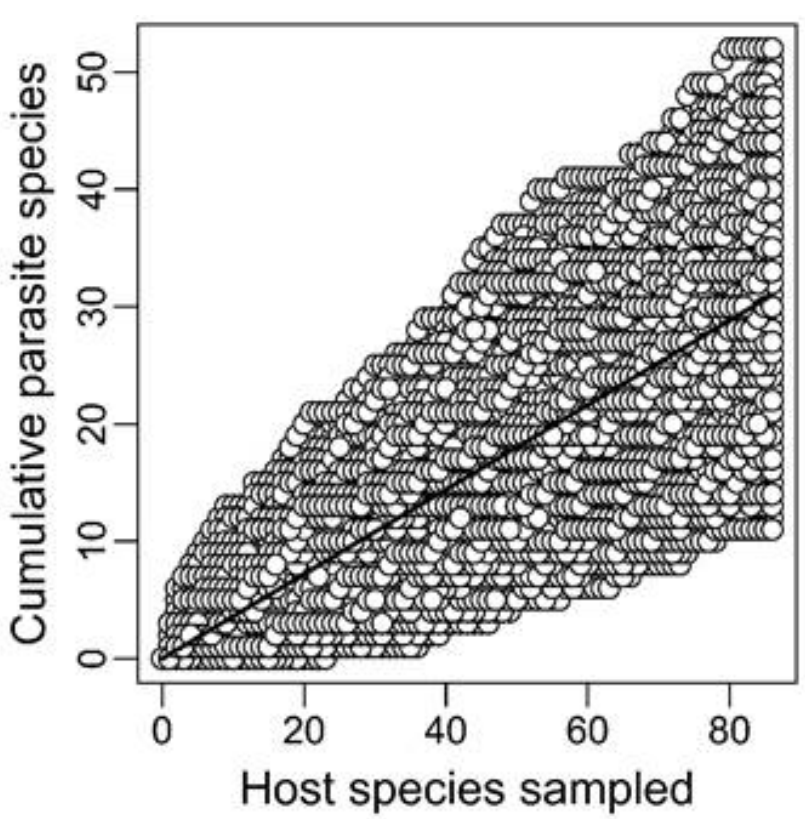

Fig. 1. The relationship between the number of apicomplexan species recovered and the number of species of Chiroptera (bat) examined as determined by Monte Carlo simulation. The open circles represent values from individual iterations of the simulations.

tified $>100$ helminth, protist and other parasite species in $R$. pipiens. However, as systematic and biological studies became more sophisticated, herpetologists recognised that leopard frogs represented a clade of 27 or more extant, and some recently extinct, species, but no host specimens had been deposited in museum collections. Consequently, there is no way to determine the specific identity of hosts reported in all those surveys other than by matching today's geographic distributions of those species with the published parasite survey results going back $>60$ years. For these and other reasons, Frey et al. (1992) recommended that a host specimen from which a parasite type specimen is collected should be correctly identified, deposited in an accredited museum, and be designated as a symbiotype host.

Host sample size. Finally, sample sizes of some hosts collected are often exceedingly small and/or the host lineage itself may be small (e.g., tree shrews). I understand it is impossible to coerce animals into your traps, but it does present an impediment to accurate forecasting of potential new parasite species yet to be discovered if only one or two specimens of a host species are captured during a survey. At the other extreme, when hundreds of hosts of many species (e.g., bats) are collected, too often species are listed only as "all uninfected" without sample sizes, or sometimes without even species names given (e.g., "388 bats, 23 species were examined, but none were infected," or "one had a coccidium").

In the 12 data sets listed above, I tried to do simple extrapolations of how many new coccidian species will be added for each new host species, when all species in the group have been examined. The quality of these estimates depends on the quality of the individual data points; that means the parasite species recovered from each host spe- cies examined and how many parasite species are found in multiple host species must be known. Unfortunately, data in individual surveys are not presented in a single uniform manner and without an indication of sampling effort, not much can be done except to make such simple calculations.

Clearly, there is a difference between recovering ten coccidian species from examining two hosts $v s$. finding ten species after examining 200 hosts. Thus, including information on effort would allow comparison between host taxa that are heavily sampled, relative to those that are under-represented, and would allow for an examination of whether there are clear patterns that differ among host taxa or if there is more variation within certain host taxa. Without data collection that records the number of host individuals examined for each host species, one cannot evaluate the error in the estimates or evaluate the significance of any differences that might be observed. As a result, ten of the 12 vertebrate groups examined here offer only 'generalised estimates' because I cannot account for sampling effort.

However, two groups, bats and tree shrews, were examined in a more analytical (statistically meaningful) manner to offer ideas to those who do surveys in the future. I asked Derek Zelmer (Professor, Biology and Geology, University of South Carolina Aiken, Aiken, Georgia, USA) to help me evaluate the bat and limited tree shrew data available and the following analyses are his work.

The Chiroptera survey data are relatively manageable because a good percentage of the surveys provided information on sampling effort that allows one to calculate the numbers for most bat species examined in these surveys, including those in which no parasites were found. First, I generated a list of the species examined, and the new parasite species that were added for each including the new data for bats (1,116 species per Wilson and Reeder 2005) and apicomplexans (those added since Duszynski 2002). The relationship between the number of bat species examined and the number of new parasite species discovered for each taxon was examined by performing 10,000 Monte Carlo simulations, drawing a bat species at random (without replacement to avoid convergence on a single number when the samples were exhausted), tabulating the cumulative coccidian species discovered with the addition of each bat species, and estimating the slope of the resulting relationship between host species examined and new parasite species discovered using least-squares linear regression. The slopes were averaged across the 10,000 iterations to produce an estimate of the rate at which new coccidian species would be discovered as novel host species are examined. In instances where coccidians were reported from more than a single bat species, that parasite species was considered novel only once in each iteration.

When a Monte Carlo simulation ran with all the data (Fig. 1) a significant positive relationship was found between host sample size and new apicomplexan taxa found (albeit with a small slope) for the bat species sampled to date. Ordering the data into three subgroups showed how sample size affected the estimated slope (Fig. 2). The $\mathrm{N}<3$ bar (33 host taxa) included surveys with sample sizes of only one or two bats (slope $=0.2725$ ); the $2<\mathrm{N}<21$ bar 
Table 1. Known number of coccidian species (Conoidasida) in 12 major vertebrate lineages and the estimated number of new apicomplexan species yet to be discovered in each host group (see text for calculations).

\begin{tabular}{|c|c|c|c|c|}
\hline \multicolumn{5}{|c|}{ Host groups } \\
\hline Examined & Approx. No. spp. ${ }^{1}$ & $\begin{array}{l}\text { No. spp. examined } \\
(\%)^{2} \text { spp./forms }\end{array}$ & Known No. apicomplexans & $\begin{array}{c}\text { Estimated No. spp./ } \\
\text { forms to be discovered }\end{array}$ \\
\hline Amphibia & 8,120 & $45(<1)$ & 90 & 16,150 \\
\hline Amphisbaenia & 198 & $4(2)$ & 11 & 543 \\
\hline Crocodylia & 27 & $17(63)$ & 62 & 36 \\
\hline Serpentes & 3,805 & $214(6)$ & 321 & 5,387 \\
\hline Chelonia & 352 & $67(19)$ & 106 & 456 \\
\hline Insectivora & 503 & $64(13)$ & 141 & 966 \\
\hline Primates & 376 & $77(20)$ & 155 & 598 \\
\hline Scandentia & 20 & $5(25)$ & 7 & 21 \\
\hline Chiroptera & 1,116 & $116(10)$ & 78 & 700 \\
\hline Lagomorpha & 91 & $23(25)$ & 128 & 381 \\
\hline Marsupiala & 331 & $85(26)$ & 155 & 443 \\
\hline Carnivora & 286 & $172(60)$ & 692 & 456 \\
\hline Totals: & 15,225 & $889(5.8)$ & 1,946 & 31,381 \\
\hline
\end{tabular}

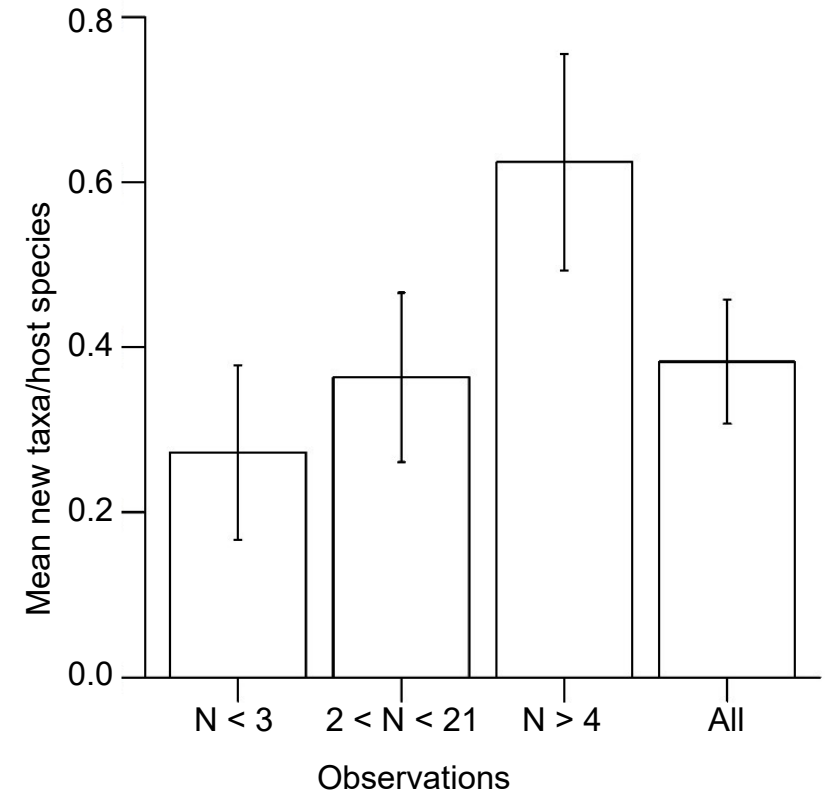

Fig. 2. Variation in expected rates of discovery of new apicomplexan species in Chiroptera (bat) hosts based on subdividing the existing survey results into three subgroups by the sample sizes employed. The rates differ significantly among all 4 groups (ANOVA). Error bars are standard deviations from the Monte Carlo simulations. $\mathrm{N}<3$ (33 host taxa) sample size 1 or 2 (slope 0.2725 ) $; 2<\mathrm{N}<21$ (33 taxa) sample sizes 3-20 (slope 0.3635); $\mathrm{N}$ $>4$ (32 taxa) sample sizes $>21$ (slope 0.6254); "All" = all observations combined (slope 0.3835 ). Error bars $=\mathrm{SD}$.

(33 taxa) included surveys with sample sizes from three to 20 bats (slope $=0.3635$ ); the $\mathrm{N}>4$ bar (32 taxa) included surveys with the highest sample sizes (slope $=0.6254$ ); and "All" included all observations combined and may be a reasonable estimate of what to expect (slope $=0.3835$ ).

The results were predictable: larger samples produced a steeper slope, with more predicted species discovered per bat species examined, but the dataset is heavily biased by the many small sample sizes. Multiplying the "All" value $(0.3835)$ by 1,030 (unsurveyed bat species) gives an estimate of 395 new coccidian species that yet may be discov- ered in the Chiroptera (vs. my "extrapolated" 700 possible new species, above, Table 1), but higher sample sizes across the board might be expected to double the "All" estimate.

The tree shrew survey data offer two immediate impediments: (i) an evolutionary lineage with only modest radiation and small numbers of species; and (ii) only a few surveys with small sample sizes. The number of surveys is an issue only because it greatly affects the confidence in the estimate, but one of the coccidians discovered, Eimeria tupaiae Mullin, Colley et Stevens, 1972, complicates the analysis because in estimating the number of new species recovered, E. tupaiae can only be a new species the first time it is found. To resolve this, three data columns were created (Fig. 3); one where E. tupaiae was first found in $T$. glis, so the examination of that genus contributed three new species; one where E. tupaiae was first found in Tupaia minor Günther, so T. glis contributed two new species and Tupaia tana Raffles contributed none, and one where E. tupaiae was first found in T. tana. Note that for the estimate, it does not matter which host species $E$. $t u$ paiae was actually discovered in, because that is a matter of historical accident, not biology. For the simulations that generate cumulative species curves, one of those columns is chosen at random, so all eventualities are covered by the simulation. Because of the small sample numbers, it was not possible to partition the data into low and high sample sizes (as with the Chiroptera data, Fig. 2), but in this case there is no significant relationship between the number of hosts examined and number of parasite species found, so there is no need to account for that (Fig. 3). The result is an estimated slope of 0.9974 new parasites per host species examined $(\mathrm{SE}=0.004106)$. The result does not differ from the estimate of (i), but now there is an error associated with the estimate.

The 12 vertebrate lineages, combined, currently represent $\sim 15,255$ extant species on our planet. Of these, only $889 / 15,255$ (5.8\%) have been examined for apicomplexans of any type and about 1,946 species/morphotypes have been written into our literature. These numbers extrapolate to a 


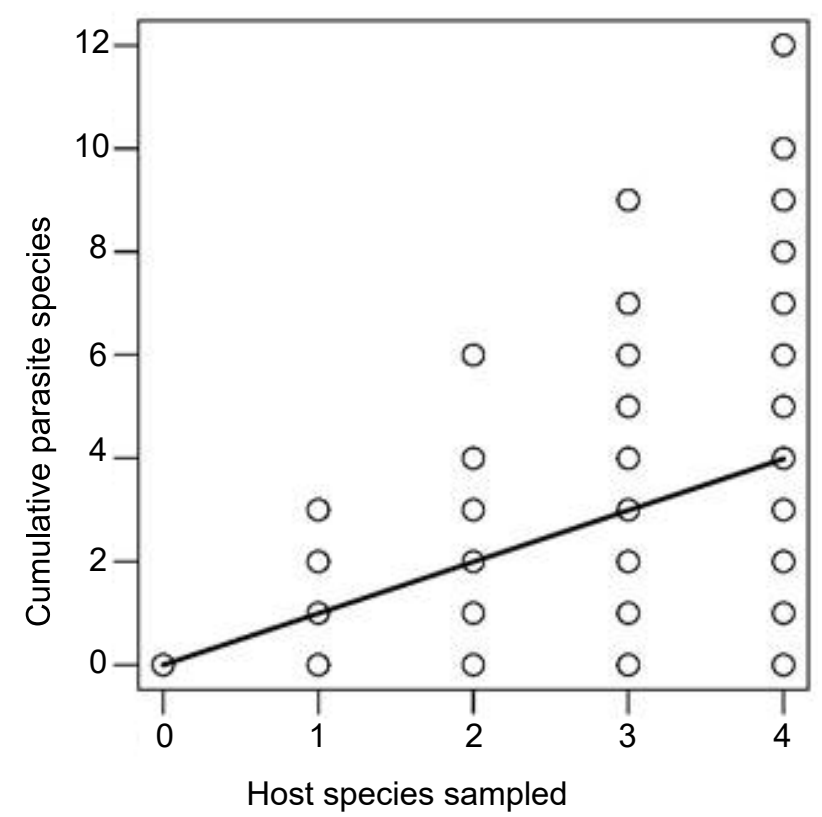

Fig. 3. The relationship between the number of apicomplexan species recovered, and the number of tree shrew species examined (see text) as determined by Monte Carlo simulations in which one column is chosen at random so all eventualities are covered by the simulation. The open circles represent values from individual iterations of the simulations. The result is an estimated slope of 0.9974 new parasites per host species examined (standard error $=0.004106$ ).

best 'guesstimate' that there still may be $\sim 31,381$ new species yet to be discovered just in these 12 groups (Table 1).

\section{What about other vertebrate and invertebrate lineages?}

The only reptile group we have not yet studied to compile a list of their apicomplexans is the Sauria (lizards). There are $\sim 5,500$ extant species of lizards; although there are probably several hundred apicomplexan species already described from lizards, no revisionary summary exists (work in progress). What about all other mammal groups, not yet studied, including the Rodentia and 15 lesser orders with a combined total of 3,180 species? Almost 300 species in about 10 genera of apicomplexans already are known in rodents (unpublished data), but there is no revisionary summary for any of these 16 orders. There are about 10,000 species of Aves; no complete revisionary summary exists for any of their orders. There are about 33,000 extant fish species on Earth. No revisionary summary exists for them and/or their apicomplexans. These remaining vertebrate groups represent $\sim 52,480$ additional extant species. If we assume there are only two apicomplexan species still to discover in each of these (yet unexamined) host species, then there are still at least an additional 105,000 apicomplexans to study; adding the 31,381 predicted new parasite species from the 12 lineages already surveyed allows me to predict that, at very minimum, there may be 135,000 new apicomplexans still to be discovered and described! Even doubling that number will be a significant underestimation, in my opinion.
And what about the invertebrates? No revisionary summaries exist for any lineage. Where do we begin with invertebrates and who will do that work?

\section{DISCUSSION}

This review summarises what we know about some of the apicomplexan species that infect 12 specific vertebrate lineages. With the numbers documented here, it can be said that the Apicomplexa is a species-rich group of protist parasites. What is species richness? Ecologists define it as the number of species in an assemblage. Further, they emphasise that species richness is a key feature of any ecological community and is central to theories about conservation, ecosystem processes, community stability, and parasite transmission (Dallas et al. 2019). Unfortunately, this review of our parasitological literature demonstrates that our knowledge of coccidian species richness is based on quite limited and non-exhaustive sampling. Uneven sampling efforts across virtually every assemblage reviewed here does not allow accurate estimates for species richness at any scale using available observational data and this lack of complete data sets severely hampers our understanding of disease processes.

Both parasite species richness (number of parasites able to infect each host species) and parasite host range (number of host species a given parasite species can infect) are critical pieces of information. A few studies have tried to estimate parasite species richness (Poulin 1998, Cooper et al. 2012), but they concentrated almost entirely on helminth species and focused on estimating the number of host species infected by a given parasitic worm (i.e., the number of susceptible host species). Host ranges are rarely estimated in real systems because the variation in the relative abundance of species, and the detection of rare species, makes it challenging - if not impossible - to confidently or accurately estimate host range. One example will serve. Dallas et al. (2017) attempted to estimate parasite host range by comparing two empirical host-parasite association databases. The first was simple occurrence data for parasites of four mammalian orders (artiodactyls, carnivores, perissodactyls, primates). Unfortunately, they used summary data from the on-line (but unpublished) Global Mammal Parasite Database (GMPD) (Nunn and Altizer 2005). This database is reasonably archaic, not having been updated in more than a decade, and it is a list of viruses, bacteria, various protists, helminths, and arthropods and all of these lineages were simply combined to be equal as just "parasites." Their second empirical database was a multi-year (1990-1998), near exhaustive sampling for small mammal parasites as part of the Sevilleta Long Term Ecological Research (LTER) Program (Duszynski 2010a) in New Mexico USA. The former dataset was composed of simple occurrence data from published literature that produced inherent biases (differential study effort, hosts of conservation concern, etc.). The Sevilleta LTER dataset consisted of a smaller number of host species $(n=24)$ that were sampled more extensively and consistently over time, and a smaller number of parasite species $(n=40)$ that were identified using established protocols by a team 
of experts (see Duszynski 2010a, for details). This study resulted in a more even distribution of parasite occurrence among host species and avoided the sampling bias inherent in the GMPD.

When doing surveys of any host group to determine the extent of their parasite fauna, sampling biases, such as the three mentioned above, can introduce hurdles that make estimating the host range of parasites particularly challenging. Additional examples of such bias can include (Dallas et al. 2017), but are not limited to, at least the following:

- Targeted sampling for a particular parasite (e.g., Sarcocystis spp., Toxoplasma gondii).

- Opportunistic sampling for certain easily acquired host species (e.g., road kills, hunter kills).

- Sampling for low frequency hosts due to rareness or habitat preferences (e.g., sampling terrestrial but not arboreal primates).

- Finding variation in parasite infection rates (e.g., hosts with low prevalence rates may be missed if the host species is also rare).

- Infection with certain parasites (e.g., T. gondii in some rodents) may alter host behaviour leading to variation in detection probability.

- Parasite detection protocols will differ by researcher (e.g., taking only blood samples); they can influence the variability in parasite detection and can further influence known (and unknown) host-parasite associations.

- Parasite host ranges are not necessarily static:

- host range may increase if novel hosts are parasitised via host-switching;

- host range may decrease with host species local extinctions;

- Evolution of host immune defences in one area may lead to the loss of a given parasite in that area, but not in another.

All these unintentional, unavoidable and unknown biases contribute to our current lack of information about parasite occurrence and prevents us from understanding parasite specificity and how it changes through time. What other factors may and can influence the number and kinds of parasites found and reported in most past surveys, such as those cited in this review, and in our future surveys?

- Immune responses stimulated by the first parasite to enter a host may influence the potential of the host to suppress the success of later arriving parasites.

- Climate change and loss of habitats are shifting host distributions resulting in the formation of novel host and parasite communities.

- Interactions between closely related apicomplexans (e.g., intestinal eimerians) may be stronger due to niche overlap, resource use, and similarity in their antigenic profiles recognised by the host's immune response.

- The timing of apicomplexan (or any parasite) infections may be critical determinants of what parasite species are found in any host tissue on the day it is collected.

- Different parasite species and/or their abundance found in a host on the day it is sampled may depend on its coinfecting parasite species.

- The confluence of a host's genetics, immune status, nutritional status, and geographical and seasonal dynamics may strongly influence the structure of its parasite community across space and time and in shifting climate conditions.

- Any individual host species will exhibit variation in susceptibility to one or more of its parasite inhabitants.

- Both extra- or intracellular gut and tissue parasites alter their occupied habitat through cell and tissue destruction and the modulation of the host immune response. This makes the order of parasite arrival important to subsequent coinfection dynamics.

Thus, sampling biases at the researcher level, insufficient sampling at the community level, and all of the uncontrollable collecting issues noted here are long-standing challenges to estimating species diversity that, in my mind, supersede the concerns of some regarding the application of "appropriate statistical procedures" for all surveys because we cannot assume that sampling is random (see Dallas et al. 2017). All the parasite databases offered here suffer from incomplete and variable sampling. Thus, it is critically important to develop appropriate methods for using these databases as effectively as we can, given resources available to us.

Tens of thousands of surveys have found and described thousands of apicomplexan species or forms and these data only raise more questions than they answer. The vast majority of field surveys in parasitology, by definition, are flawed in multiple ways (e.g., small sample sizes, one-time events, etc.). And when we look at long-term survey data of parasites in wild animals, the literature "well" is virtually empty. Compared with insect surveys (e.g., bees, monarch butterflies, etc.), that have documented precipitous population declines over multiple decades (Sánchez-Bayo and Wyckhuys 2019), we have virtually no baseline data for long-term population studies of parasite occurrence in wild animal populations. Thus, the predictive accuracy of our survey data can only increase with more detailed parasite lists that are accurate from individual hosts that have been systematically collected, hopefully over extended periods of time, and correctly identified and archived by specialists in their fields. I conclude this review with the hope we will increase our knowledge in the future and with some questions to suggest "what we do not know, that we do not know." There will be answers needed to questions that we do not even know how to ask yet, and there may be many apicomplexan parasites we do not currently know how to classify yet.

- Will vertebrate and invertebrate biologists ever embrace working with parasitologists? Collaborations no longer should be limited to sharing ideas with the biologist in the lab next door because science is increasingly an interdisciplinary, transdisciplinary, inter-institutional, and international endeavour. Systematists, taxonomists and epidemiologists need to move quickly in that direction, and do so together.

- When will we have the parasite data to give us the predictive capacity to alert field biologists to which parasite genera and species they may find in a particular host species or group of species, in any and every environment, and how and where best to look for them 
in the animals they collect?

- Disease agents in humans and their domestic animals (e.g., T. gondii, N. caninum) are 'spilling over' and increasing the threat to wild animal populations (e.g., sea otters, kangaroos), especially in endangered or marginal habitats. How many other zoonoses exist that we do not yet understand or cannot even imagine (think COVID-19)?

- How many new life cycles remain undiscovered?

- Is there a parasite apocalypse coming? Does anyone care about the mass extinctions of parasite species that occur with the ever-dwindling numbers of endangered animal species?

- If parasites were removed from a fragile ecosystem with limited resources, would it tip the balance toward extinction for many or all of the plants and animals in that ecosystem?

- Our ability to understand the geographic origin and isolation of many host species and their parasite species is being diminished greatly by the world's wildlife trafficking and pet trades. How can parasitologists contribute to helping solve these problems?

So many questions to ponder, so little time, ... and so few people trained to do it.

Acknowledgements. My colleagues who helped do revisionary taxonomy of the vertebrate groups summarised here deserve all the credit. Thanks to Matthew G. Bolek, Department of Integrative Biology, Oklahoma State University (OSU), Stillwater, Oklahoma, USA; he has been a friend for decades, both as a student at the University of Nebraska and as a faculty member at OSU, and he was instrumental in helping compile literature for our monograph on the coccidia of amphibians (2007). Thanks to Lee Couch, wife, friend, lover, and constant supporter in all my written work, and my co-author on our revisionary systematic book on the coccidia of rabbits (2013). Thanks to Jana Kvičerová, Department of Parasitology, University of South Bohemia, České Budějovice, Czech Republic, my friend and colleague for decades since I first served as the outside referee on her undergraduate honours thesis and, years later, I had the honour to conduct her dissertation defence examination (which she finished with distinction) in České Budějovice. She played a central role, especially with her keen eye for detail and her knowledge of Russian, in helping write our recent book on the coccidia of carnivores (2018). To Norman D. Levine (1912-1999; Todd 2000), formerly at the University of Illinois, whom I became friends with through my $\mathrm{PhD}$ advisor, William C. Marquardt, when Norman was the Editor of the (former) Journal of Protozoology. Dr. Levine bequeathed a good portion of his professional library (aka, paper reprints) to me when he retired, including a partial/incomplete manuscript on some coccidians known from primates and it was the stimulus for our monograph on primate and scandentia coccidian parasites (1999). Thank you, Chris McAllister, Science and Mathematics Division, Eastern Oklahoma State College, Idabel, Oklahoma USA, a longtime friend, colleague, and co-author on numerous taxonomic papers on the coccidia of vertebrates. It was Chris' idea to summarise the coccidia of the legless lizards (Amphisbaenia) of the world (2019) because it was such a tractable group to work with; he also played an important role in assembling the literature for our later monograph on crocodile coccidia (2020). Thanks to Johnica J. Morrow, Department of Physical and Life Sciences, Chadron State College, Chadron, Nebraska USA, whom I first met via email when she was a MS student at Midwestern State University, Wichita, Texas USA, and I later took her to her first parasitology meeting at Lake Texoma, Oklahoma; Johnica helped me collect the literature on turtle coccidia, which later resulted in our little soft-cover book on the coccidia of turtles of the world (2014). Sincere thanks to Damien Scott, PT, MS, OCS, Statesville, Georgia USA, who in the fall, 1993 took a field biology course with me and got hooked on research. As an undergraduate in my lab, he started working on bat coccidia and then went on to finish his MS with distinction in my lab. As a graduate student he did the bulk of the work on collecting the world's literature on the coccidian species known from bats. His work was essential to my monograph on the coccidia of bats (2002). Thank you R. Scott Seville, Department of Zoology and Physiology, University of Wyoming, Casper, Wyoming, USA, a friend, colleague, and co-author for more than three decades who, along with Jana Kvičerová, endured my surly and demanding nature for almost two years while we worked on the coccidia of carnivores book (2018). A sincere thank to Marisa Tellez, Co-Founder and Executive Director, Crocodile Research Coalition (CRC), Belize, whom I first met when I visited her at the CRC in 2018. Marisa had previously (2013) published a check list of crocodile parasites so I went to Belize to discuss a possible collaboration with me and Chris McAllister to write a major review on all apicomplexans of the Crocodylia, a major effort that we recently completed (2020). I can never thank or say enough good about Steven J. Upton (1953-2010; Duszynski 2010b). Steve finished his MS with me (1981), then went to Auburn University to complete his PhD with Bill Current (1983), then went to the University of Texas-El Paso (UTEP) for two years as a visiting assistant professor, before taking his final academic position at Kansas State University, Manhattan, Kansas, USA, in the fall of 1986. Steve and I became lifelong friends, we travelled the world together to meet colleagues who studied coccidian biology and visit their libraries (Brazil, France, Hungary, Russia, others). In addition to his contributions on primates and Scandentia (1999), insectivores (2000), and amphibians (2007), we worked feverishly to complete our book on coccidia of snakes (2010) just before his death. I still miss him terribly. Thanks to Wade D. Wilson, who finished his MS degree with me (1998), later completed his PhD in ichthyology, and now works for the NM Department of Fish and Game, Roswell NM; Wade helped with literature retrieval for our primate/Scandentia monograph (1999). I am very grateful, especially, to Derek Zelmer, Professor, Biology and Geology, University of South Carolina Aiken (USCA), Aiken, South Carolina, USA, who did all of the 'real' statistical evaluations in this manuscript. Finally, in the fall 2018, my colleague, friend and sometime mentor, Xun Suo, National Animal Protozoa Laboratory and College of Veterinary Medicine, China Agricultural University, Beijing, China, invited me to attend and give a lecture at the 8th International Symposium of Parasitology and 17th National Conference of Parasitology combined meeting in 2019. I was honoured to accept his generous offer and I gave the opening plenary lecture at this joint meeting, held 16-19 October 2019, on the campus of Hebei Normal University, Shijiazhuang City (Hebei Province), China. This manuscript is a result of that talk. 


\section{REFERENCES}

Abdel-Baki A.-A.S., Al-Quraishy S., Duszynski D.W. 2014a: Choleoeimeria salaselensis sp. n. (Apicomplexa: Eimeriidae) from the gall bladder of the horned viper Cerastes gasperettii (Serpentes: Viperidae) in Saudi Arabia. Folia Parasitol. 61: 201-205.

Abdel-Baki A.-A.S., Al-Quraishy S., Zhang J.Y. 2014b: Redescription of Haemogregarina garnhami (Apicomplexa: Adeleorina) from the blood of Psammophis schokari (Serpentes: Colubridae) as Hepatozoon garnhami n. comb. based on molecular, morphometric and morphologic characters. Acta Parasitol. 59: 294-300.

Adl S.M, Bass D., Lane C.E., Lukeš J., Schoch C.L., Smirnov A., Agatha S., Berney C., Brown M.W., Burk F., Cardenas P., ČepičKa I., Chistyakova L., del Campo J., Dunthorn M., Edvardsen B., Eglit Y., Guillou L., Hampl V., Heiss A.A., Hoppenrath M., James T.Y., KarnKowsKa A., Karpov S., Kim E., Kolísko M., Kudryavtsev A., Lahr D.J.G., Lara E., Le Gall L., Lynn D.H., Mann D.G., Massana R., Mitchell E.A.D., Morrow C., Park J.S., Pawlowski J.W., Powell M.J., Richter D.J., Rueckert S., Shadwick L., Shimano S., Spiege, F.W., Torruella G., Youssef N., Zlatogursky V., Zhang Q. 2019: Revisions to the classification, nomenclature, and diversity of eukaryotes. J. Euk. Microbiol. 66: 4-119.

Adl S.M., Simpson A.G.B., Farmer M.A., Andersen R.A., Anderson O.R., Barta J.R., Bowser S.S., Brugerolle G., Fensome R.A., Fredericg S., James T.Y., Karpov S., Kugrens P., Krug J., Lane C.E., Lewis L.A., Lodge J., LynN D.H., Mann D.G., Mccourt R.M., Mendoza L., Moestrup O., Mozley-Standridge S.E., Nerad T.A., Shearer C.A., Smirnov A.V., Spiegel F.W., TAylor M.F.J.R. 2005: The new higher-level classification of eukaryotes with emphasis on the taxonomy of protists. J. Euk. Microbiol. 52: 399-451.

Adl S.M., Simpson A.G.B., Lane C.E., Lukeš J., Bass D., Bowser S.S., Brown M.W., Burki F., Dunthorn M., Hampl V., Heiss A., Hoppenrath M., Lara E., Gall L.L., Lynn D.H., McManus H., Mitchell E.A.D., Mozley-Stanridge S.E., Parfrey L.W., Pawlowski J., Rueckert S., Shadwick L., Schoch C.L., Smirnov A., Spiegel F.W. 2012: The revised classification of eukaryotes. J. Euk. Microbiol. 59: 429-493.

Alyousif M.S., Al-Anazi A.D., Al-Shawa Y.R. 2003: Eimeria gasperettii n. sp. (Apicomplexa: Eimeriidae) from the horned viper, Cerates cerastes gasperettii in Saudi Arabia. J. Egypt Soc. Parasitol. 33: 711-716.

Bacciarini L.N., Völlm J., Janovsky M., Kappler A., Gröne A. 2001: Acute disseminated toxoplasmosis in a colony of squirrel monkeys (Saimiri boliviensis). Eur. J. Vet. Pathol. 7: 67-73.

Banlunara W., Kesdangskonwut S., Kongmekee P., SomMANUSTWEechai A. 2013: Coccidiosis in a greater slow loris (Nycticebus coucang). Thai J. Vet. Med. 43: 269-272.

Bartošová-Sojková P., Oppenheim R.D., Soldati-Favre D., LUKEŠ J. 2015: Epicellular apicomplexans: parasites 'on the way in.' PLoS Pathogens 11: 1-9.

Beaver P.C., Gadgil R.K., Morera P. 1979: Sarcocystis in man: a review and report of five cases. Am. J. Trop. Med. Hyg. 28: 819-844.

Bezerra-Santos M.A.B., Nogueira B.C.F., Ramos R.A.N., Duszynski D.W., de Araújo J.V., Campos A.K. 2020: Eimeria spp. (Apicomplexa: Eimeriidae) in Didelphis aurita Wied-Neuwied, 1826 (Didelphimorphia: Didelphidae) and description of a new species infecting this opossum. Zootaxa 4878: 572-580.

Boulard Y. 1975: Etude morphologique des coccidies (Adeleidae) Klossiella killicki $\mathrm{n}$. sp. chez de microchiropterae africans et
Klossiella tejerai Scorza, 1957, chez un marsupial sud-americain. Bull. Mus. Nat. Hist., Ser. 3, No. 284, Zool. 194: 83-89.

Brooks D.R. 1993: Extending the symbiotype concept to host voucher specimens. J. Parasitol. 79: 631-633.

Catão-Dias J.L., Epiphanio S., Kierulff M.C.M. 2013: Neotropical primates and their susceptibility to Toxoplasma gondii: new insights for an old problem. In: J.F. Brinkworth, K. Pechenkina (Eds.), Primates, Pathogens, and Evolution. Develoments in Primatology: Progress and Prospects Book 38. Springer, New York, pp. 253-289.

Cedillo-Peláez C., Rico-Torres C.P., Salas-Garrido C.G., Correa D. 2011: Acute toxoplasmosis in squirrel monkeys (Saimiri sciureus) in Mexico. Vet. Parasitol. 180: 368-371.

Chapman P.A., Owen H., Flint M., Traub R.J., Cribb T.H. Mills P.C. 2016: Molecular characterization of coccidia associated with an epizootic in green sea turtles (Chelonia mydas) in South East Queensland, Australia. PLoS ONE 11: e0149962.

Charles-Smith L.E., Cowen P., Schopler R. 2010: Environmental and physiological factors contributing to outbreaks of Cryptosporidium in coquerel's sifaka (Propithecus coquereli) at the Duke Lemur Centre: 1999-2007. J. Zoo Wildl. Med. 41: $438-444$.

Cooper N., Kamilar J.M., Nunn C.L. 2012. Host longevity and parasite species richness in mammals. PLoS ONE 7: e42190.

Couch L., LaAk konen J., Goodman S., Duszynski D.W. 2011: Two new eimerians (Apicomplexa) from insectivorous mammals in Madagascar. J. Parasitol. 97: 293-296.

Cui P., Liu H., Fang S., Gu X., Wang P., Liu C., Tao G., Liu X., Suo X. 2017: A new species of Eimeria (Apicomplexa: Eimeriidae) from Californian rabbits in Hebei Province, China. Parasitol. Int. 66: 677-680.

D’Agostino J. 2014: Chapter 34. Insectivores (Insectivora, Macroscelidea, Scandentia). In: E.A. Miller, M.E. Fowler (Eds.), Fowler's Zoo and Wild Animal Medicine, Volume 8, E-Book. Elsevier Saunders, St. Louis, pp. 275-281.

Dallas T., Huang S., Nunn C., Park A.W., Drake J.M. 2017: Estimating parasite host range. Proc. R. Soc. B 284: 20171250.

Dallas T.A, Laine A.-L., Ovaskainen O. 2019: Detecting parasite associations within multi-species host and parasite communities. Proc. R. Soc. B 286: 20191109.

Daszak P., Ball S.J., Streicker D.G., Jones C.G., Snow K.R. 2011a: A new species of Caryospora Léger, 1904 (Apicomplexa: Eimeriidae) from the endangered Round Island boa Casarea dussumieri (Schlegel) (Serpentes: Bolyeridae) of Round Island, Mauritius: an endangered parasite? Syst. Parasitol. 78: 117-122.

Daszak P., Ball S.J., Streicker D.G., Snow K.R. 2011b: A new species of Eimeria (Apicomplexa: Eimeriidae) from the western hognose snake, Heterodon nasicus (Serpentes: Xenodontidae), from Texas. J. Parasitol. 97: 463-465.

Debenham J.J. 2017: Intestinal protozoa in wildlife: parasite transmission at the wildlife-human-domestic animal interface. $\mathrm{PhD}$ thesis, Norwegian University of Life Sciences Adamstuen, Oslo, Norway, $113 \mathrm{pp}$.

Dubey J.P. (ED.) 2020: Coccidiosis in Livestock, Poultry, Companion Animals, and Humans. CRC Press, Boca Raton, Florida, 381 pp.

Dubey J.P., Calero-Bernal R., Rosenthal B.M., Speer C.A., FAYer R. 2015: Sarcocystis of Animals and Humans. Second Edition. CRC Press, Inc., Boca Raton, Florida, 501 pp.

Dubey J.P., Evason K.J., Walther Z. 2019: Endogenous development of Cystoisospora belli in intestinal and biliary epithelium of humans. Parasitology 146: 865-872.

Dubey J.P., Hamir A.N., Sonn R.J., Topper M.J. 1998: Cryptosporidiosis in a bat (Eptesicus fuscus). J. Parasitol. 84: 622-623. 
Dubey J.P., Hemphill A., Calero-Bernal R., Schares G. 2017: Neosporosis in Animals. CRC Press, Inc., Boca Raton, Florida, 448 pp.

Dubey J.P., Kramer L.W., Weisbrode S.E. 1985: Acute death associated with Toxoplasma gondii in ring-tailed lemurs. J. Am. Vet. Med. Assoc. 187: 1272-1273.

Dubey J.P., Markovits J.E., Killary K.A. 2002: Cryptosporidium muris-like infection in stomach of cynomolgus monkeys (Macaca fascicularis). Vet. Pathol. 39: 363-371.

Dubey J.P., Wong M.M. 1978: Experimental Hammondi hammondi infection in monkeys. J. Parasitol. 64: 551-552.

Duszynski D.W. 2002: Coccidia (Apicomplexa: Eimeriidae) of the Mammalian Order Chiroptera. Special Publication of the $\mathrm{Mu}-$ seum of Southwestern Biology, No. 5, First Impressions, Inc., Albuquerque, New Mexico, 42 pp.

DUSZYNSKI D. 2010a: Rodent parasite data for the Sevilleta National Wildlife Refuge, New Mexico (1990-1998). Long Term Ecological Research Network. Available at http://dx.doi.org/10.6073/ pasta/b2f1f0dd39da440d6ee17300c9044989.

Duszynski D.W. 2010b: Steve J. Upton: June 14, 1953-July 29, 2010. J. Parasitol. 96: 1235-1236.

Duszynski D.W. 2016: The Biology and Identification of the Coccidia (Apicomplexa) of Marsupials of the World. Academic Press, London, $241 \mathrm{pp}$.

Duszynski D.W., Couch L. 2013: The Biology and Identification of the Coccidia (Apicomplexa) of Rabbits of the World. Academic Press, London, 340 pp.

Duszynski D.W., ECKerlin R.P., MCCARThy T.J. 2003: Eimeria species from Cryptotis shrews (Insectivora: Soricidae) with description of a new species. J. Parasitol. 89: 974-977.

Duszynski D.W., GaRdNer S.L. 1991: Fixing coccidian oocysts is not an adequate solution to the problem of preserving protozoan type material. J. Parasitol. 77: 52-57.

Duszynski D.W., Kvičerová J., Seville R.S. 2018: The Biology and Identification of the Coccidia (Apicomplexa) of Carnivores of the World. Academic Press, London, 712 pp.

Duszynski D.W., McAllister C.T., Tellez M. 2020: The coccidia (Apicomplexa) of the Archosauria (Crocodylia: Eusuchia) of the world. J. Parasitol. 106: 90-122.

Duszynski D.W., Morrow J.J. 2014: The Biology and Identification of the Coccidia (Apicomplexa) of Turtles of the World. Academic Press, London, 210 pp.

DusZYNSKi D.W., Upton S.J. 2000: Coccidia (Apicomplexa: Eimeriidae) of the Mammalian Order Insectivora. Special Publication of the Museum of Southwestern Biology, No. 4, University of New Mexico Printing Services, Albuquerque, New Mexico, $67 \mathrm{pp}$.

Duszynski D.W., Upton S.J. 2010: The Biology of the Coccidia (Apicomplexa) of Snakes of the World. A Scholarly Handbook for Identification and Treatment. CreateSpace Independent Publishing Platform, Scotts, Valley, California, 433 pp.

Duszynski D.W., Upton S.J., Bolek M. 2007: Coccidia (Apicomplexa: Eimeriidae) of the amphibians of the world. Zootaxa (Magnolia Press) 1667: 1-77.

Duszynski D.W., Wilson W.D., Upton S.J., Levine N.D. 1999: Coccidia (Apicomplexa: Eimeriidae) in the Primates and Scandentia. Int. J. Primatol. 20: 761-797.

Eberhard M.L. da Silva A.J., Lilley B.G., Pieniazek N.J. 1999: Morphologic and molecular characterization of new $C y$ clospora species from Ethiopian monkeys: C. cercopitheci $\mathrm{sp}$. n., C.colobi sp. n., and C. papionis sp. n. Emerg. Infect. Dis. 5: 651-658.

Ekanayake D.K., Arulkanthan A., Horadagoda N.U., SanJeevani G.K.M., Kieft R., Gunatilake S., Dittus W.P.J. 2006: Prevalence of Cryptosporidium and other enteric parasites among wild non-human primates in Polonnaruwa, Sri Lanka. Am. J. Trop. Med. Hyg. 74: 322-329.

Elsheikna H.M. 2009: Has Sarcocystis neurona Dubey et al., 1991 (Sporozoa: Apicomplexa: Sarcocystidae) cospeciated with its intermediate hosts? Vet. Parasitol. 163: 307-314.
Fayed H.M., Shazly M.A.A., El-Monem S.A. 2011: Life cycle of Eimeria rousetti sp. nov. (Alveolata: Apicomplexa: Eimeriidae) infecting the frugivorous bat, Rousettus aegyptiacus Geoffroy, 1810 (Mammalia: Chiroptera: Pteropodidae) in Egypt. J. Anim. Sci. 7: 292-305.

Ferguson S.D., Wellehan J.F.X. Jr., Frasca S. Jr., Innis C.J., Harris H.S., Miller M., Weber E.S., Walden H.S, Greiner E.C., Merigo C., Stacy B.A. 2016: Coccidial infection of the adrenal glands of leatherback sea turtles (Dermochelys coriacea). J. Wildl. Dis. 52: 874-882.

Frenkel J.K., Dubey J.P., Miller N.L. 1970: Toxoplasma gondii in cats: fecal stages identified as coccidian oocysts. Science 167: 893-896.

Frey J.K., Yates T.L., Duszynski D.W., Gannon W., Gardner S.L. 1992: Designation and curatorial management of type host specimens (symbiotypes) for new parasite species. J. Parasitol. 78: 930-932.

Frost D.R. 2020: Amphibian Species of the World: An Online Reference. American Museum of Natural History, New York, USA. Version 6.0, 01/24/20. E-Database: http://research.amnh. org/herpetology/amphibia/index.html.

Gaetano T.J., Danzy J., Mtshall M.S., Theron N., Schmitt C.A., Grobler J.P., Freimer N., Turner T.R. 2014: Mapping correlates of parasitism in wild South African vervet monkeys (Chlorocebus aethiops). S. Afr. J. Wildl. Res. 44: 56-70.

Gómez M.S., Gracenea M., Gosalbez P., Feliu C., Ensenat C., Hidalgo R. 1992: Detection of oocysts of Cryptosporidium in several species of monkeys and in one prosimian species at the Barcelona Zoo. Parasitol. Res. 78: 619-620.

Gómez M.S., Torres J., Gracenea M., Fernandez-Morán J. Gonzalez-Moreno O. 2000: Further report on Cryptosporidium in Barcelona zoo mammals. Parasitol. Res. 86: 318-323.

Gonzalez-Moreno O., Hernandez-Aguilar R.A., Piel A.K., Stewart F.A., Gracenea M., Moore J. 2013: Prevalence and climatic associated factors of Cryptosporidium sp. infections in savanna chimpanzees from Ugalla, Western Tanzania. Parasitol. Res. 112: 393-399.

Graczyk T.K., Cranfield M.R., Dunning C., Strandberg J.D. 1998: Fatal cryptosporidiosis in a juvenile captive African hedgehog (Atelerix albiventris). J. Parasitol. 84: 178-180.

Gruber A.D., Schulze C.A., Brügmann M., Pohlenz J. 1996: Renal coccidiosis with cystic tubular dilation in four bats. Vet. Pathol. 33: 442-445.

HNIDA J.A. 2015: A new species of Isospora Schneider, 1881 (Apicomplexa: Eimeriidae) from Morafka's desert tortoise Gopherus morafkai (Testudines: Testudinidae). Syst. Parasitol. 92: 219-222.

Hofmannová L., Jirke̊ M., Řeháková M., Kvičerová J. 2018: Two new species of Eimeria (Apicomplexa: Eimeriidae) in Philippine tarsier (Tarsius syrichta). Eur. J. Protistol. 66: 77-85.

Hofmannová L., Kvičerová J., Bizková K, Modrú D. 2019: Intranuclear coccidiosis in tortoises - discovery of its causative agent and transmission. Eur. J. Protistol. 67: 71-76.

Honigberg B.M., Balamuth W., Bovee E.C., Corliss J.O., Gojdics M., Hall R.P., Kudo R.R., Levine N.D., Lobblich A.R. JR., Weiser J. 1964: A revised classification of the phylum Protozoa. J. Protozool. 11: 7-20.

Hu J.-J., Meng Y., Guo Y.-M., Liao J.-Y., Song J.-L. 2012: Completion of the life cycle of Sarcocystis zuoi, a parasite from the Norway rat, Rattus norvegicus. J. Parasitol. 98: 550-553.

Hutchison W.M., Dunachie J.F., SiIm J.C., Work K. 1970: Coccidia-like nature of Toxoplasma gondii. Brit. Med J. 1: 142 144.

de Jesus R.F., Rodrigues G.M., Silva E.M., Carneiro A.J.B., Franke C.R., Cunha R. De M., Gondim L.F.P. 2017: Toxoplasmatinae parasites in bats from Bahia State, Brazil. J. Wildl. Dis. 53: 144-147.

JirkŮ M., JirkŮ M., Oborník M., Lukeš J., ModrÝ D. 2009: Goussia Labbe, 1896 (Apicomplexa, Eimeriorina) in Amphibia: 
Diversity, biology, molecular phylogeny and comments on the status of the genus. Protist 160: 123-136.

Karim M.R., Zhang S., Jian F., Li J., Zhou C., Zhang L., Sun M., YAng, G., Zou F., Dong H., Li J. 2014: Multilocus typing of Cryptosporidium spp. and Giardia duodenalis from non-human primates in China. Int. J. Parasitol. 44: 1039-1047.

Klumpp S.A., Anderson D.C., McClure H.M., Dubey J.P. 1994: Encephalomyelitis due to a Sarcocystis neurona-like protozoan in a rhesus monkey (Macaca mulatta) infected with simian immunodeficiency virus. Am. J. Trop. Med. Hyg. 51: 332-338.

Kusewitt D.E., Wagner J.E., Harris P.D. 1977: Klossiella sp. in the kidney of two bats (Myotis sodalis). Vet. Parasitol. 3 : 365-369.

KváČ M., Hofmannová L., Hlásková L., KvĚtoñová, D Vítovec J., McEvoy J., SAK B. 2014: Cryptosporidium erinacei n. sp. (Apicomplexa: Cryptosporidiidae) in hedgehogs. Vet. Parasitol. 201: 9-17.

Kváč M., Hořická A., Sak B., Prediger J., Salát J., Širmarová J., BartoničKa T., Clark M., Chelladurai J.R.J.J., Gillam E., McEvoy J. 2015: Novel Cryptosporidium bat genotypes III and IV in bats from the USA and Czech Republic. Parasitol. Res. 114: 3917-3921.

Labbé A. 1899: Sporozoa. Das Tierreich. Eine Zusammenstellung und Kennzeichnung der Rezenten Tierformen. Vol. 5. R. Friedländer and Sohn, Berlin, $180 \mathrm{pp}$.

Levine N.D. 1970: Taxonomy of the Sporozoa. J. Parasitol. 56: 208-209.

Levine N.D. 1980a: Dorisa n. gen. (Protozoa, Apicomplexa, Eimeriidae). J. Parasitol. 66: 11

LEvine N.D. 1980b: Some corrections of coccidian (Apicomplexa: Protozoa) nomenclature. J. Parasitol. 66: 830-834.

Levine N.D. 1988: The Protozoan Phylum Apicomplexa, Vol. I. CRC Press, Inc., Boca Raton, Florida, 203 pp.

Levine N.D., Corliss J.O., Cox F.E.G., Deroux G., Grain J., Honigberg B.M., Leedale T.G.F., Loeblich III A.R., Lom J., Lynn D., Merinfeld E.G., Page F.C., Poljansky G., Sprague V., Vávra J., Wallace F.G. 1980: A newly revised classification of the Protozoa. J. Protozool. 27: 37-58.

Levine N.D., Ivens V., Kruidenier F.J. 1955: Two new species of Klossia (Sporozoa: Adeleidae) from a deer mouse and a bat. J. Parasitol. 41: 623-629.

Lim Y.A.L., Ngui R., Shukri J., Rohela M., Naim H.M. 2008 Intestinal parasites in various animals at a zoo in Malaysia. Vet. Parasitol. 157: 154-159.

LindSAY D.S., Dubey J.P. 2014: Toxoplasmosis in wild and domestic animals. In: L.M. Weiss and K. Kim (Eds.), Toxoplasma gondii. The Model Apicomplexan: Perspectives and Methods. Academic Press, New York, pp. 193-215.

Lv L.B., Ma Y.H., Zou F.C., Liu S.G., Yang J.F. 2011: Detection of parasitic infection in domesticated tree shrew and the determination of de-worming effect by examining the fecal samples. Acta Lab. Anim. Sci. Sin. 6: 522-524.

LynCh A.J., Duszynski D.W. 2008: Species of coccidia (Apicomplexa: Eimeriidae) in shrews from Alaska, U.S.A., and northeastern Siberia, Russia, with description of two new species. J. Parasitol. 94: 883-888.

Marangi M., Koehler A.V., Zanzani S.A., Manfredi M.T., Brianti E., Giangaspero A., Gasser R.B. 2015: Detection of Cyclospora in captive chimpanzees and macaques by a quantitative PCR-based mutation scanning approach. Parasit. Vectors 8: 274-278.

Marchiondo A.A., Duszynski D.W. 1978: Permanent light microscopy slides of Eimeria nieschulzi oocysts. J. Parasitol. 64: 163-164.

Marchiondo A.A., Duszynski D.W. 1988: On the status of Eimeria nieschulzi oocysts embedded in resin eleven years ago: a permanent method for preserving coccidian oocysts. J. Parasitol. 74: 737-739.

McAllister C.T., Burt S., Seville R.S., Robison H.W. 2011: A new species of Eimeria (Apicomplexa: Eimeriidae) from the eastern pipistrelle, Perimyotis subflavus (Chiroptera: Vespertilionidae), in Arkansas. J. Parasitol. 97: 896-898.

McAllister C.T., Duszynski D.W. 2019: The coccidia (Apicomplexa: Eimeriidae) of legless lizards (Squamata: Laertoidea: Amphisbaenia) of the world. J. Parasitol. 105: 113-123.

McAllister C.T., Motriuk-Smith D., Kerr C.M. 2018: Three new coccidians (Cyclospora, Eimeria) from eastern moles, Scalopus aquaticus (Mammalia: Soricomorpha: Talpidae) from Arkansas, USA. Syst. Parasitol. 95: 271-279.

McAllister C.T., Roehrs Z.P., Seville R.S. 2012a: A new species of Caryospora (Apicomplexa: Eimeriidae) from the flathead snake, Tantilla gracilis (Ophidia: Colubridae), in southeastern Oklahoma. J. Parasitol. 98: 640-642.

McAllister C.T., Seville R.S. 2017: A new eimerian (Apicomplexa: Eimeriidae) from southern short-tailed shrews, Blarina carolinensis (Bachman) (Soricimorpha: Soricidae: Soricinae) from southeastern Oklahoma, USA. Syst. Parasitol. 94: 711-716.

McAllister C.T., Seville R.S., Bursey C.R. 2017: Helminth (Cestoda, Nematoda) and coccidian (Apicomplexa: Eimeriidae) parasites of the eastern small-footed myotis, Myotis leibii (Chiroptera: Vespertilionidae) from Arkansas, with a description of a new species of Eimeria. Acta Parasitol. 62: 377-381.

McAllister C.T., Seville R.S., Connior M.B. 2015: A new species of Isospora (Apicomplexa: Eimeriidae) from the eastern coachwhip, Coluber flagellum flagellum (Reptilia: Ophidia) from Oklahoma. Acta Parasitol. 60: 466-470.

McAllister C.T., Seville R.S., Connior M.B. 2016: A new coccidian (Apicomplexa: Eimeriidae) from midland brown snake, Storeria dekayi wrightorum Trapido (Ophidia: Colubridae) from Arkansas, USA. Syst. Parasitol. 93: 77-82.

McAllister C.T., Seville R.S., Roehrs Z.P. 2012b: A new species of Eimeria (Apicomplexa: Eimeriidae) from the northern myotis, Myotis septentrionalis (Chiroptera: Vespertilionidae), in Oklahoma. J. Parasitol. 98: 1003-1005.

McAllister C.T., Upton S.J. 2009: Two new species of Eimeria (Apicomplexa: Eimeriidae) from eastern red bats, Lasiurus borealis (Chiroptera: Vespertilionidae), in Arkansas and North Carolina. J. Parasitol. 95: 991-993.

McAllister C.T., Upton S.J., Bursey C.R. 2004: Parasites (Coccidia, Trematoda, Nematoda) from selected bats of Arkansas. J. Arkansas Acad. Sci. 58: 133-135.

Meerburg B.G., De Craeye S., Dierick K., Kijlstra A. 2012: Neospora caninum and Toxoplasma gondii in brain tissue of feral rodents and insectivores caught on farms in the Netherlands. Vet. Parasitol. 184: 317-320.

Milek J.A., Seville S. 2003: Species of Eimeria and Isospora (Apicomplexa: Eimeriidae) from shrews (Insectivora: Soricidae) in northwestern Wyoming, U.S.A. Comp. Parasitol. 70: 72-77.

ModrÝ D., JiRKŮ M., HŮRKOVÁ L. 2005: A new coccidian parasite (Apicomplexa: Eimeriidae) from the rufous elephant shrew, Elephantulus rufescens, from Kenya. Afr. Zool. 40: 327-329.

Mohamed H.A., Molyneux D.H. 1984: Elleipsisoma thomsoni Franca, 1912: an apicomplexan parasite in the red blood cells of the mole (Talpa europaea). Parasitology 89: 407-415.

Mohamed H.A., Molyneux D.H., Wallbanks K.R. 1987: A coccidian in haemogamasid mites; possible vectors of Elleipsisoma thomsoni Franca, 1912. Ann. Parasitol. Hum. Comp. 62: 107-116.

Mosier D.A., Oberst R.D. 2000: Cryptosporidiosis: a global challenge. Ann. N. Y. Acad. Sci. 916: 102-111.

Morgan U.M., Sturdee A.P., Singleton G., Gomez M.S., Gracenea M., Torres J., Hamilton S.G., Woodside D.P., Thompson R.A. 1999: The Cryptosporidium "mouse" genotype is conserved across geographic areas. J. Clin. Microbiol. 37: 1302-1305.

Mühldorfer K., Speck S., Wibbelt G. 2011: Diseases in free-ranging bats from Germany. BMC Vet. Res. 7: 61-72

Murakoshi F., Koyama K. Akasaka T., Horiuchi N., Kato K. 2018: Molecular and histopathological characterization of Cryp- 
tosporidium and Eimeria species in bats in Japan. J. Vet. Med. Sci. 80: 1395-1399.

Murakoshi F., Recuenco F.C., Omatsu T., Sano K., Taniguchi S., Masangkay J.S., Alviola P., Eres E., Cosico E., Alvarez J., Une Y., Kyuwa S., Sugiura Y., Kato K. 2016: Detection and molecular characterization of Cryptosporidium and Eimeria species in Philippine bats. Parasitol. Res. 115: 1863-1869.

Muriuki S.M.K., Farah I.O., Kagwiria R.M., Chai D.C., Nuamunge G., Suleman M., Olobo J.O. 1997: The presence of Cryptosporidium oocysts in stools of clinically diarrhoeic and normal nonhuman primates in Kenya. Vet. Parasitol. 72: $141-147$.

Nery-Guimarẽes F., Franken A.J. 1971: Toxoplasmosis in non-human primates. II. Attempts at experimental infection of Macaca mulatta, Cebus apella, and Callithrix jacchus; antibody studies in various species of Platyrrhinus. Mem. Inst. Oswaldo Cruz 69: 97-120.

Nery-Guimarães F., Franken A.J., Chagas W.A. 1971: Toxoplasmosis in non-human primates. I. Natural infections in $\mathrm{Maca}$ ca mulatta and Cebus apella. Mem. Inst. Oswaldo Cruz 69: 77-96.

NowaK R.M., Paradiso J.L. 1983: Walker's Mammals of the World. Foruth edition. Johns Hopkins University Press, Baltimore, Maryland, $1921 \mathrm{pp}$.

Nunn C.L., Altizer S.M. 2005: The Global Mammal Parasite Database: an online resource for infectious disease records in wild primates. Evol. Anthropol. 14: 1.

Parsons M.B., Travis D., Lonsdorf E.V., Lipende I., Roellig D.M., Collins A., Kamenya S., Zhang H., Xiao L., GilLESPIE T.R. 2015: Epidemiology and molecular characterization of Cryptosporidium spp. in humans, wild primates, and domesticated animals in the Greater Gombe Ecosystem, Tanzania. PLoS Negl. Trop. Dis. 9: e0003529.

Pinto C.M., Helgen K.M., Fleischer R.C., Perkins S.L. 2013: Hepatozoon parasites (Apicomplexa: Adeleorina) in bats. J. Parasitol. 99: 722-724.

Poulin R. 1998. Comparison of three estimators or species richness in parasite component communities. J. Parasitol. 84: 485490.

Roberts J.F., Wellehan Jr. J.F.X., Weisman J.L., Rush M., Childress A.L., Lindsay D.S. 2015: Massive muscular infection by a Sarcocystis species in a South American rattlesnake (Crotalus durissus terrificus). J. Parasitol. 101: 386-389.

Sak B., Petrželková K.J., Květoňová,D., MynáŘová, A., Shutt, K.A., Pomajbíková K., Kalousová B., Modrý D., Benavides J., Todd A., Kváč M. 2013: Long-term monitoring of microsporidia, Cryptosporidium and Giardia infections in Western lowland gorillas (Gorilla gorilla gorilla) at different stages of habituation in Dzanga Sangha Protected Areas, Central African Republic. PLoS ONE 8: e71840.

Salzer J.S., Rwego I.B., Goldberg T.L., Kuhlenschmidt M.S., Gillespie T.R. 2007: Giardia sp. and Cryptosporidium sp. infections in primates in fragmented and undisturbed forest in western Uganda. J. Parasitol. 93: 439-440.

SÁnchez-BAyo F., Wyckhuys K.A. 2019: Worldwide decline of the entomofauna: a review of its drivers. Biol. Conserv. 232: $8-27$.

De Santana Miglionico M.T., Viana L.A. 2017: A new species of Caryospora Léger, 1904 (Apicomplexa: Eimeriidae) from the Guanabara spotted night snake Siphlophis pulcher (Raddi) (Reptilia: Dipsadidae) in the Atlantic Forest, Brazil. Syst. Parasitol. 94: 621-625.

Santos S.V., Pena H.F., Talebi M.G., Teixeira R.H., Kanamura C.T., Diaz-Delgado J., Gennari S.M., Catão-Dias J.L. 2018: Fatal toxoplasmosis in a southern muriqui (Brachyteles arachnoides) from São Paulo State, Brazil: pathological, immunohistochemical, and molecular characterization. J. Med. Primatol. 47: 124-127.
SaOud M.F.A., Ramdan N.F., Mohammed S.H., Fawzi S.M. 1996: On two new haemogregarines (Protozoa: Apicomplexa) from colubrid and Elapidae snakes in Egypt. Qatar Univ. Sci. J. 16: $127-139$.

Schiller S.E., Webster K.N., Power M. 2016: Detection of Cryptosporidium hominis and novel Cryptosporidium bat genotypes in wild and captive Pteropus hosts in Australia. Infect. Genet. Evol. 44: 254-260.

SCHNEIDER C.R. 1966: Experimental infection of short-tailed bats, Carollia perspicillata, with Besnoitia panamensis (Protozoa: Toxoplasmatidae). J. Parasitol. 52: 703.

Scott N.J. JR., Hillis D.M. 1990: Correction of the name of the host of the trematode Lageronia jimenezi Iruegas-Buentello and Salinas-Lopez 1989. Southwestern Nat. 34: 569.

Sheffield H.G., Melton, M.L. 1970: Toxoplasma gondii: the oocyst, sporozoite, and infection of cultured cells. Science 167: 892-893.

de Silva A.J., Cacciò S., Williams K., Won K.Y., Nace E.K., Whittier C., Pieniazek N.J., Eberhard M.L. 2003: Molecular and morphological characterization of a Cryptosporidium genotype identified in lemurs. Vet. Parasitol. 111: 297-307.

SinHA C.K. 1979: Dorisiella harpia n. sp. from hairy-winged bat. Ind. J. Parasitol. 3: 173-175.

Sмiтh J. 2020: $30 \times 30$ : protect $30 \%$ of the planet's land and water by 2030. Nature Consererv. 34: 47-51.

Song J., Kim C.Y., Chang S.N., Abdelkader T.S., Han J., Kim T.H., Он H., Lee J.M., Кim D.S., Kim J.T., Он H.S. 2015: Detection and molecular characterization of Cryptosporidium spp. from wild rodents and insectivores in South Korea. Kor. J. Parasitol. 53: 737-743.

Springer A., Kappeler P.M. 2016: Intestinal parasite communities of six sympatric lemur species at Kirindy Forest, Madagascar. Primate Biol. 3: 51-63.

Sricharern W., Inpankaew T., Keawmongkol S., Supanam J., Stich R.W., Jittapalapong S. 2016: Molecular detection and prevalence of Giardia duodenalis and Cryptosporidium spp. among long-tailed macaques (Macaca fascicularis) in Thailand. Infect. Genet. Evol. 40: 310-314.

Stein B. 2020: Lifelines of the planet. Natl. Wildl. 58: 22-25.

Teichroeb J.A., Kutz S.J., Parker U., Thompson R.C.A., Sicotte P. 2009: Ecology of the gastrointestinal parasites of Colobus vellerosus at Boageng-Fiema, Ghana: possible anthropozoonotic transmission. Am. J. Phys. Anthropol. 140: 498-507.

Telford S.R., Norton T.M., Moler P.E., Jensen J.B. 2009: A new Haemogregarina species of the alligator snapping turtle, Macrochelys temminckii (Testudines: Chelydridae) in Georgia and Florida that produces macromeronts in circulating erythrocytes. J. Parasitol. 95: 208-214.

Tinnin D.S., Jensen E.T., Batsaikhan N., Ganzorig S., GARDNER S.L. 2012b: New species of Eimeria (Apicomplexa: Eimeriidae) from Ochotona hyperborea and Ochotona pallasi (Lagomorpha, Ochotonidae) in Mongolia. Erforsch. Biol. Res. Mongol. (Halle/Saale) 12: 125-134.

Tinnin D.S., Jensen E.T., Batsaikhan N., Gardner S.L. 2012a: Coccidia (Apicomplexa: Eimeriidae) from Vespertillo murinus and Eptesicus gobiensis (Chiroptera: Vespertillionidae) in Mongolia and how many species of Coccidia occur in bats? Erforsch. Biol. Res. Mongol. (Halle/Saale) 12: 117-124.

TodD K.S. JR. 2000: In memoriam: Norman Dion Levine (19121999). J. Eukaryot. Microbiol. 47: 96-97.

Tomé B., Maia J.P.M.C., Har Ris D.J. 2013: Molecular assessment of apicomplexan parasites in the snake Psammophis from North Africa: do multiple parasite lineages reflect the final vertebrate host diet? J. Parasitol. 99: 883-887.

Uetz P. 2007: The Reptile Database: http://www.reptile-database. org/.

Uetz P., Freed P., Hošek J. (Eds.) 2020: The Reptile Database. Available: http://www.reptile-database.org. Accessed 10 February 2020. 
UilenberG G. 1970: Quelques protozoaires parasites de mammifères sauvages à Madagascar avec la description de trois nouveaux sporozoaires. Ann. Parasitol. Hum. Comp. 45: 183-194.

Verma S.K., Lindsay D.S., Mowery J.D., Rosenthal B.M., DuBEy J.P. 2017: Sarcocystis pantherophisi n. sp., from eastern rat snakes (Pantherophis alleghaniensis) as definitive hosts and interferon gamma gene knockout mice as experimental intermediate hosts. J. Parasitol. 103: 547-554.

Viana L.A., Winck G.R., Coelho C.D., Flausino W., Duarte Rocha C.F. 2013: A new species of Caryospora Léger, 1904 (Apicomplexa: Eimeriidae) from the snake Philodryas olfersii Lichtenstein (Colubridae) from a coastal habitat in Brazil. Syst. Parasitol. 85: 195-199.

Wang W., CaO L., He B., Li J., Hu T., Zhang F., Fan Q., Tu C., LIU Q. 2013: Molecular characterization of Cryptosporidium in bats from Yunnan Province, southwestern China. J. Parasitol. 99: 1148-1150.

Wilson D.E., ReEder D.A.M. 1993: Mammal Species of the World: A Taxonomic and Geographic Reference. Second Edition. Smithsonian Institution Press, Washington, D.C., 1,207 pp.

Wilson D.E., Reeder D.A.M. 2005: Mammal Species of the World: A Taxonomic and Geographic Reference. Third Edition. Smithsonian Institution Press, Washington, D.C., 2,142 pp.

Wünschmann A., Wellehan J.F.X Jr., Armien A., Bemrick W.J., Barnes D., Averbeck G.A., Roback R., Schwabenlander M., D’Almeida E., Joki R., Childress A.L., Cortinas R., Gardiner C.H., Greiner E.C. 2010: Renal infection by a new coccidian genus in big brown bats (Eptesicus fuscus). J. Parasitol. 96: 178-183.

Xiang Z., Rosenthal B.M., He Y., Wang W., Wang H., Song J., Shen P.Q., Li M.L., Yang Z. 2010: Sarcocystis tupaia, sp. nov., a new parasite species employing tree shrews (Tupaiidae, Tupaia belangeri chinensis) as natural intermediate hosts. Parasitol. Int. 59: 128-132.

Yabsley M.J., Jordan C.N., Mitchell S.M., Norton T.M., LindSAY D.S. 2007: Seroprevalence of Toxoplasma gondii, Sarcocystis neurona, and Encephalitozoon cuniculi in three species of lemurs from St. Catherines Island, GA, USA. Vet. Parasitol. 144: $28-32$.

Ye J., Xiao L., Li J., Huang W., Amer S.E., Guo Y., Roellig D., FENG Y. 2014: Occurrence of human-pathogenic Enterocytozoon bieneusi, Giardia duodenalis and Cryptosporidium genotypes in laboratory macaques in Guangxi, China. Parasitol. Int. 63: 132-137.

Zaman V., GoH T.K. 1970: Isolation of Toxoplasma gondii from Malayan tree shrew. Trans. R. Soc. Trop. Med. Hyg. 64: 462.

Zhao G.-H., Cong M.-M., Bian Q.-Q., Cheng W.-Y., Wang R.-J., Qi M., Zhang L.-X., Lin Q., ZhU X.-Q. 2013: Molecular characterization of Cyclospora-like organisms from golden snub-nosed monkeys in Qinling Mountain in Shaanxi Province, northwestern China. PLoS ONE 8: e58216.

Ziegler P.E., Wade S.E., Schaaf S.L., Stern D.A., NadareSKi C.A., Монамmed H.O. 2007: Prevalence of Cryptosporidium species in wildlife populations within a watershed landscape in southeastern New York State. Vet. Parasitol. 147: 176-184.

Cite this article as: Duszynski D.W. 2021: Biodiversity of the Coccidia (Apicomplexa: Conoidasida) in vertebrates: what we know, what we do not know, and what needs to be done. Folia Parasitol. 68: 001. 